\title{
Influencia de cuerpos discordantes de distinta cohesión en la geometría estructural de fajas plegadas y corridas: aproximación sobre la base de un modelamiento analógico
}

\author{
Matías Villarroel ${ }^{1}$, Pamela Jara $^{2}$, Reynaldo Charrier ${ }^{1,3}$ \\ ${ }^{1}$ Carrera de Geología, Universidad Andres Bello, Sazie 2119, Santiago, Chile. \\ mvillarroel.lastra@gmail.com; rcharrier@unab.cl \\ ${ }^{2}$ Departamento de Ingeniería en Minas, Facultad de Ingeniería, Universidad de Santiago de Chile, Av. Bernardo O'Higgins 3363 \\ Estación Central, Santiago, Chile. \\ pamela.jara@usach.cl \\ 3 Departamento de Geología, Universidad de Chile, Plaza Ercilla 803, Santiago, Chile. \\ * Autor de correspondencia: pamela.jara@usach.cl
}

\begin{abstract}
RESUMEN. Las heterogeneidades incluidas en el material constituyente de una faja plegada y corrida (FPC) en formación, afectan la geometría y disposición de las estructuras que la conforman. En este trabajo se utiliza la modelación analógica para estudiar el efecto que ejerce sobre la configuración estructural de una FPC la presencia de cuerpos cohesivos, tales como bloques de basamento, intrusivos u otros cuerpos cristalinos de alta competencia, y que, por lo tanto, oponen mayor resistencia a la deformación contraccional que las rocas estratificadas del entorno. La influencia de estos cuerpos sobre el patrón de deformación de la FPC se estudió mediante la incorporación de cuerpos discordantes de diferente cohesión dentro de una secuencia estratificada, granular y de cohesión despreciable. Se realizaron dos sets de experimentos en que los cuerpos discordantes presentan cohesión baja (Co1) y alta (Co2), respectivamente. Los resultados experimentales muestran (i) la tendencia del patrón estructural, o sea, de las fallas inversas en secuencia, a curvarse según la geometría del cuerpo cohesivo, y (ii) una migración del frente de deformación hacia la zona del antepaís, aun cuando el cuerpo cohesivo no aflore. En el primer caso (Co1) las fallas cortan al cuerpo cohesivo, en tanto que en el segundo (Co2) este no es fallado, sino que es transportado hacia el frente de deformación mediante un nivel de despegue. La comparación de los resultados de estos modelos análogos con ejemplos naturales de diferentes escalas, muestran un alto grado de coincidencia en los patrones estructurales reconocidos en ambos casos. Una de las características de estos patrones es la tendencia de las fallas a evitar el cuerpo cohesivo y adoptar en su rumbo la geometría del borde distal del cuerpo. Se sugiere considerar la presencia de cuerpos más competentes que su entorno para explicar las curvaturas que se reconocen en patrones estructurales naturales de las FPC.
\end{abstract}

Palabras clave: Modelación analógica, Cuerpos cohesivos, Fajas plegadas y corridas, Cuerpos cohesivos en fajas plegadas y corridas.

\begin{abstract}
Role of cohesive discordant bodies on fault-and-thrust belts deformation pattern: an approach based on analogue modelling. Lithological heterogeneities in a rock series deformed by the development of a fold-andthrust belt (FTB) affects the pattern of the resulting structures. We present a series of analogue experiments to determine the effect caused on the deformation pattern of a FTB by the presence of cohesive bodies, like plutons or basement blocks that oppose greater resistance than the host rocks to contractional deformation. The influence of these bodies on the deformation pattern of the FTB was studied by incorporating discordant bodies with different cohesions within a stratified granular sequence with negligible cohesion. We describe two sets of experiments in which the inserted body presents low (Co1) and high (Co2) cohesion respectively. The experiments show a tendency of the structural pattern to
\end{abstract}


curve around the inserted body and to migrate towards the deformation front or the foreland, even when the cohesive body is not exposed. In the first case (Co1) the thrusts cut across the cohesive body, while in the second one (Co2) the cohesive body is not faulted, but transferred towards the deformation front along a basal detachment. Comparison of these results with natural examples at different scales shows a high degree of coincidence in the structural patterns recognized in both cases. Two of the main characteristics of these patterns are the tendency of the thrust faults traces to avoid the cohesive body and adopt the geometry of its distal edge. In order to explain curvatures in natural structural patterns in fold-and-thrust belts, we suggest consider the presence of unexposed bodies with higher strength than their environment.

Keywords: Analogue model, Fold-and-thrust belt, Cohesive bodies, Cohesive blocks in FTB.

\section{Introducción}

Las fajas plegadas y corridas representan elementos esenciales en la arquitectura de cadenas de montañas desarrolladas en márgenes continentales activos. Las estructuras que las conforman flanquean, generalmente, uno o ambos bordes de la cadena y, en este último caso, permiten conferir al orógeno el carácter de doble vergencia (Torrini y Speed, 1989; Muñoz, 1992; Roeder y Chamberlin, 1995; Chaumillon y Mascle, 1997; McClay y Whitehouse, 2004; Martínez y Cristallini, 2017). Tanto las fajas plegadas y corridas como los prismas de acreción, se forman en condiciones de deformación contraccional determinadas durante regímenes tectónicos compresivos y por su geometría en perfil se las puede asimilar a una cuña de Coulomb (Davis et al., 1983; Dahlen, 1990); estas últimas se caracterizan por estar constituidas por una sucesión imbricada de escamas tectónicas (Fig. 1). Sin embargo, los ambientes tectónicos en que se forman difieren fundamentalmente unos de otros: (1) Los prismas de acreción se originan en la zona de subducción, en el contacto entre la corteza oceánica y la continental y (2) Las fajas plegadas y corridas, en cambio, se forman en el (o los) frente(s) de deformación del orógeno, y la deformación que afecta a las rocas comprometidas es esencialmente frágil (Álvarez-Marrón et al., 1993; Giambiagi et al., 2003; Turienzo, 2010).
Las fajas plegadas y corridas incluyen rocas de diferentes edades formadas antes o durante la evolución del orógeno que, en el momento de su incorporación a la faja plegada y corrida, se pueden encontrar expuestas o cerca de la superficie. Un ejemplo de lo anterior son las fajas plegadas y corridas del borde oriental de los Andes del Sur (e.g., de Sierras Subandinas, La Ramada, Aconcagua, Malargüe, Agrio, Chos-Malal, de Magallanes y Fueguina). En la generación de estas fajas se distingue entre aquellas en las que el basamento está involucrado en la deformación (estilo piel gruesa) mediante la inversión tectónica de fallas preexistentes, y aquellas formadas exclusivamente por la generación de nuevos corrimientos creados por la compresión orogénica por encima de un nivel de despegue (estilo piel delgada) (Fig. 1). En el sistema de fajas plegadas y corridas que bordean a los Andes Centrales hacia el frente orogénico existen algunas que se diferencian de otras por presentar estilos estructurales diferentes; en particular, la Faja Plegada y Corrida de Aconcagua (Giambiagi et al., 2003), y la Faja Plegada y Corrida de las Sierras Subandinas (Ramos, 1999), que son típicamente de piel delgada y que aprovechan conspicuos niveles estratificados particularmente dúctiles.

Por el hecho de comprometer con frecuencia rocas sedimentarias de ciclos orogénicos y sistemas de rift anteriores, como también rocas de la cuenca de antepaís asociada al avance del frente orogénico,

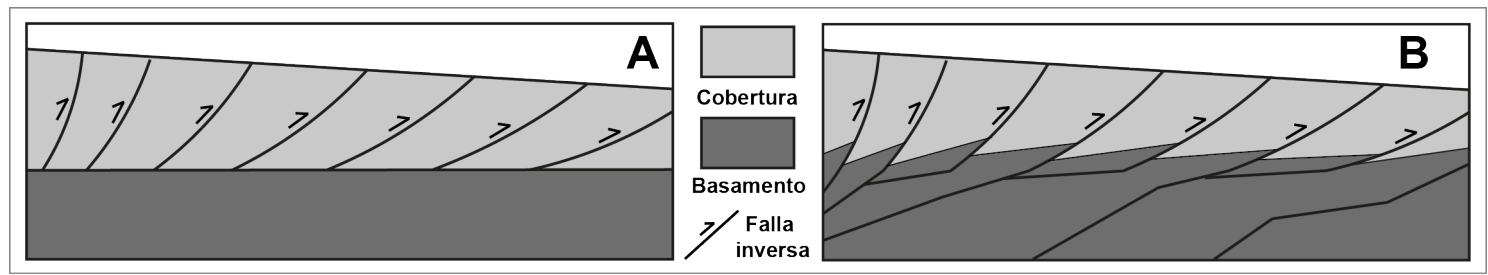

FIG. 1. Ilustración esquemática de una faja plegada y corrida. A. De piel delgada; B. De piel gruesa. 
la estructuración de las fajas plegadas y corridas favorece la generación de condiciones estructurales apropiadas para alojar yacimientos de hidrocarburos (Kozlowski et al., 1997; Abdollahie Fard et al., 2006). Debido al interés que presentan las fajas plegadas y corridas por su importancia, tanto en la evolución de las cadenas de montañas como en la prospección de recursos económicos, aportamos nuevos antecedentes sobre el efecto que ejercen cuerpos geológicos con reologías contrastantes emplazados en las secuencias de rocas estratificadas involucradas en estas fajas. En nuestra opinión, estos antecedentes contribuirán al mejor conocimiento de la geometría y cinemática de las estructuras presentes en las fajas plegadas y corridas y, por extensión, a los estudios geotectónicos de los dominios estructurales asociados.

Diversas investigaciones se han realizado para comprender los factores que influyen en las características de la deformación de una faja plegada y corrida (Buiter, 2012; Graveleau et al., 2012, entre otros). En estos, la modelación analógica ha sido una metodología fundamental, pues permite aislar el parámetro de interés y comparar su efecto en sistemas simplificados de deformación con el fin de comprender su importancia en el proceso dinámico (Schellart y Strak, 2016). Entre estos factores se han considerado, por ejemplo, la presencia de estructuras heredadas, el espesor de la secuencia sedimentaria, la orientación del esfuerzo compresivo. (Coward et al., 1991; Pinto et al., 2010; Bonini et al., 2012; Jara et al., 2015, 2018). Sin embargo, en su mayoría, no se incluye el papel de cuerpos heterogéneos de mayor resistencia a la deformación que el entorno. La presencia de cuerpos ígneos cristalinos en secuencias de rocas estratificadas sujetas a deformación ha sido estudiada de manera experimental a partir de la inyección de materiales viscosos, lo que ha dado, principalmente, información respecto de su modo de emplazamiento o su efecto en la deformación de la secuencia previa o contemporánea a la intrusión, pero, en estos casos, el cuerpo ígneo es más joven o sincrónico al evento de deformación (e.g., Galland et al., 2003, 2006; Acocella y Tibaldi, 2005; Martínez et al., 2016).

El tratamiento que se ha dado, en general, a la presencia de cuerpos de mayor resistencia a la deformación que las rocas sedimentarias de su entorno, se ha realizado con cuerpos considerados indeformables y que actúan como un backstop, que generan, entre otras cosas, retrocorrimientos o fallas fuera de secuencia (Buchanan y McClay, 1991; Mitra, 1993; McClay, 1995; Yamada y McClay, 2003, 2004; entre otros). A raíz de la falta de estudios de modelamiento analógico que consideren el contraste de competencia entre cuerpos discordantes y el medio en que se encuentran inmersos, surge la necesidad de comprender cómo se comporta estructuralmente una zona que presente estas características ante un evento de deformación.

\subsection{Objetivo}

En esta contribución se estudia, a partir de experimentos analógicos, la influencia que ejerce en las rocas comprometidas en la formación de una faja plegada y corrida la presencia en ellas de cuerpos rocosos más resistentes a la deformación. Experimentalmente, esto se modela en términos de una mayor cohesión $(\mathrm{Co})$ de los cuerpos, es decir, tratados como material rocoso susceptible de ser deformado de manera frágil. Estos cuerpos oponen una mayor resistencia a la deformación que la secuencia de rocas estratificadas que los contienen. Se propone que el contraste de competencia entre cuerpos discordantes y cohesivos y su entorno, correspondería a un factor importante en la evolución estructural de una región (momento, ubicación y disposición de estructuras) ante procesos de deformación compresiva. El conjunto de estructuras resultantes de la deformación compresiva será mencionado en adelante como "faja plegada y corrida" (FPC). Estas fajas son sistemas complejos que, como se ha señalado, presentan una amplia distribución en los frentes andinos de deformación (Giambiagi et al., 2003).

\section{Metodología}

Para estudiar este tipo de sistema complejo (FPC), se ha optado por la modelación analógica. Esto permite aislar el parámetro de interés y, por lo tanto, simplificar el problema al no verse alterado el prototipo por otros factores, los que pueden ser motivo de otras investigaciones (e.g., estructuras previas, orientación de esfuerzos). Se presentan en esta contribución los resultados de dos series de modelos analógicos que se diferencian por la distinta cohesión $(\mathrm{Co})$ de un cuerpo cilíndrico respecto de su entorno. En ambos casos estos cuerpos son más cohesivos que la secuencia estratificada en la cual están insertos, lo que permite estudiar el efecto de 
su presencia y comparar su efecto dado que uno de los modelos contiene un cuerpo con una resistencia igual a la mitad $(\mathrm{Co} 1)$ del otro $(\mathrm{Co} 2=2 \times \mathrm{Co} 1)$. Esta simplificación del problema permite observar y comparar el rol que tiene la presencia de un cuerpo cohesivo ante la deformación de una secuencia estratificada de cohesión despreciable (a escala del modelo y ampliamente utilizada para la deformación de niveles frágiles de la corteza) en la generación de una FPC.

La comparación de los patrones estructurales se basó en los rasgos superficiales resultantes, como también internos, por medio de secciones o perfiles perpendiculares al rumbo principal de las estructuras (i.e., paralelas a la dirección del esfuerzo principal mayor). Se efectuó también un cotejo con patrones estructurales presentes en FPC naturales.

\subsection{Modelación analógica}

Para que la reproducción de un experimento analógico adquiera coherencia con respecto al fenómeno natural que se desea investigar, se debe respetar el escalamiento proporcional de ciertos parámetros como la geometría, el material empleado, tiempo transcurrido, la velocidad de deformación, y los esfuerzos, etc. (Hubbert, 1937; Ramberg, 1981). Conforme con esto, el modelamiento analógico permite entender tanto la evolución de un proceso tectónico como el efecto que ejerce sobre este un parámetro físico en particular, dentro de un contexto controlado de laboratorio, a escalas de tiempo y longitud de segundos a horas y de milímetros a metros, respectivamente (Davy y Cobbold, 1991; Schellart y Strak, 2016). La materialización del diseño experimental o la elección de los materiales por utilizar son decisiones que involucran una simplificación del proceso geológico representado (Twiss y Moores, 2007). Según pruebas de cizalle y compresión uniaxial, las rocas frágiles corticales tienen un rango de cohesión (Co) entre $\sim 5$ y $180 \mathrm{MPa}$ y un ángulo de fricción interna $(\Phi)$ entre $\sim 25$ y $45^{\circ}$ (e.g., Lama y Vutukuri, 1978; Schellart, 2000). De manera que, al escalar la cohesión del material en la misma proporción que los esfuerzos, se puede obtener la similitud dinámica entre el prototipo natural y el modelo (Horsfield, 1977; Davy y Cobbold, 1988; Cobbold y Jackson, 1992).

El material analógico más ampliamente utilizado a escala de la litósfera corresponde a la arena seca de cuarzo. Dado su comportamiento conforme a la ley de Coulomb, permite simular el actuar de las rocas de la corteza superior (e.g., Krantz, 1991; Schellart, 2000; Lohrmann et al., 2003; Panien et al., 2006; Gomes, 2013). Si bien se han utilizado exitosamente otros materiales (e.g., polvo de sílice, polvo de arcilla y materiales húmedos) para representar el contraste de cohesión en secuencias estratificadas (Ellis y McClay, 1988; McClay, 1990; Krantz, 1991; Gartrell, 1997; Konstantinovskaia y Malaville, 2005; Galland et al., 2006; Bonnet et al., 2007), el tratamiento que se le ha dado a la representación del basamento cristalino o a cuerpos de mayor cohesión que el entorno, es generalmente de carácter rígido, con el empleo de bloques indeformables de madera o láminas de aluminio (e.g., Buchanan y McClay, 1991; McClay y Buchanan, 1992; Mitra, 1993; Yamada y McClay, 2003, 2004). Esto limita la generación y reactivación de estructuras a una geometría predeterminada otorgada por el material indeformable.

Payrola (2012) utilizó una mezcla de arena y gelatina (arena gelatinizada) para simular basamento cristalino en la representación de pliegues oblicuos. Bureau et al. (2014) da cuenta de que la concentración de gelatina controla la cohesión del material. Esta mezcla funciona adecuadamente para representar capas o cuerpos de alta cohesión, debido a que, en términos reológicos, mantiene las propiedades de fricción que otorga la arena y aumenta la cohesión por la unión de granos producto de la incorporación de gelatina (Bureau et al., 2014). Sobre la base de estos antecedentes, en este estudio se utiliza arena seca de cuarzo para representar la secuencia estratificada que rodea al cuerpo de alta cohesión, mientras que este último se representa mediante una mezcla de la misma arena, pero con gelatina en distintas proporciones. Los parámetros mecánicos de estos materiales y su escalamiento, se detallan en el apartado siguiente.

\subsection{Procedimiento experimental}

Se ejecutaron dos series de modelos experimentales que incluyen la presencia de cuerpos cilíndricos insertos en el centro del paquete granular ( $\mathrm{Co} 1 \mathrm{y}$ Co2 con baja y alta cohesión, respectivamente) (Fig. 2). La arena utilizada posee un ángulo de fricción interna $(\Phi)$ de $\sim 33^{\circ}$, una cohesión (Co) menor a $100 \mathrm{~Pa}$ y un tamaño de grano menor a 600 micrones (Tabla 1). La densidad del material 


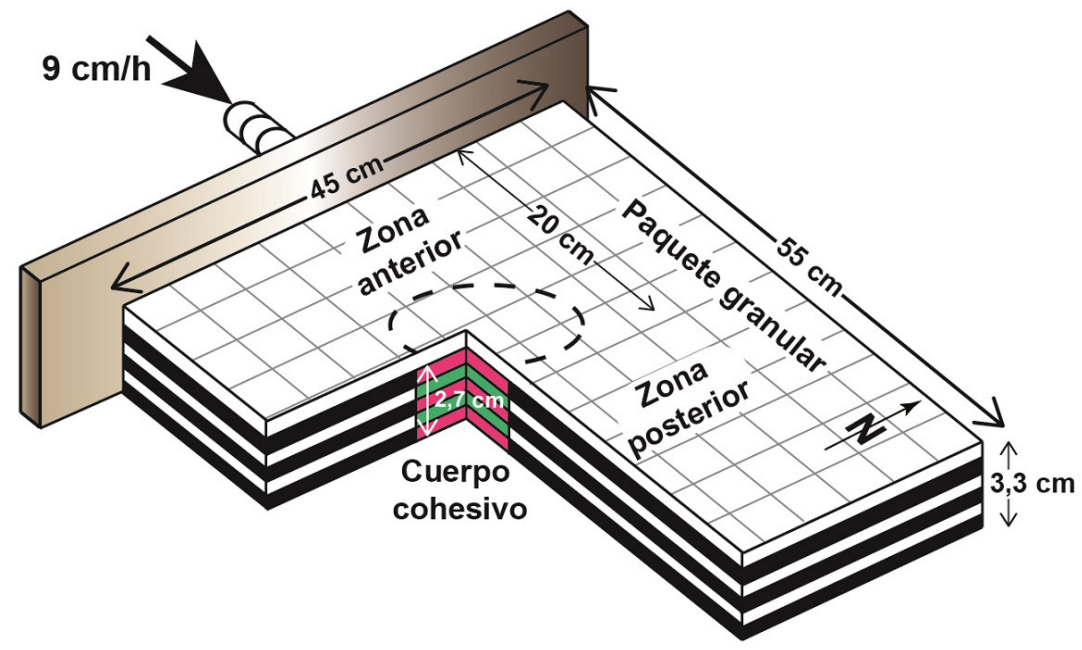

FIG. 2. Arreglo experimental y parámetros fijos de la modelación. Ambos modelos se construyeron de manera idéntica con excepción de las características mecánicas del cuerpo inserto (ver texto para mayor detalle).

TABLA 1. PROPIEDADES DE LOS MATERIALES UTILIZADOS Y PROPORCIÓN DE GELATINA EN LAS MEZCLAS.

\begin{tabular}{ccccc}
\hline Material & $\begin{array}{c}\text { Tamaño de los granos } \\
(\boldsymbol{\mu m})\end{array}$ & $\begin{array}{c}\text { Cohesión } \\
(\mathbf{P a})\end{array}$ & $\begin{array}{c}\text { Ángulo de fricción } \\
\text { interna }\end{array}$ & $\begin{array}{c}\text { Proporción de } \\
\text { gelatina }(\mathbf{g} / \mathbf{l})\end{array}$ \\
\hline Arena seca de cuarzo & $<600$ & $<100$ & $\sim 33^{\circ}$ & - \\
$\begin{array}{c}\text { Arena gelatinizada } \\
\text { "baja" }\end{array}$ & $<600$ & $785 \pm 50$ & $\sim 33^{\circ}$ & 1,5 \\
Arena gelatinizada & & & $\sim 33^{\circ}$ & 3,0 \\
\hline
\end{tabular}

análogo es equivalente a la densidad de la roca, por lo tanto, la razón de escalamiento entre el modelo y la naturaleza es igual a uno (Twiss y Moores, 2007; Bureau et al., 2014). Por otro lado, para el material cohesivo se usó Agar Agar gel (aditivo E406) en forma de polvo, proveniente del alga roja Gracilia verrucosa, que es soluble en agua hirviendo y se transforma en gel a medida que se enfría, lo cual permite adherir las partículas del material granular y rellenar los intersticios como un pegamento. Un aumento en la concentración de gelatina de 1,0 g/l resulta en un incremento de $490 \mathrm{~Pa}$ en la cohesión del material (Bureau et al., 2014). Para representar el rango aproximado de cohesión de las rocas naturales entre los 50 y $150 \mathrm{MPa}$, se utilizaron dos proporciones de gelatina (baja y alta) correspondientes a 1,5 y 3,0 $\mathrm{g} / \mathrm{l}$, lo cual significa un incremento de cohesión en el material de aproximadamente 785 y $1.520 \mathrm{~Pa}$, respectivamente. Los parámetros de escalamiento de los modelos análogos (Tabla 2) se basan en el procedimiento usado por Twiss y Moores (2007) y Pollard y Fletcher (2005).

El aparato experimental consiste en una mesa de acero sobre la cual se desplaza una pared móvil que es empujada a velocidad constante mediante un sistema combinado de servomotor y servo driver (Acevedo et al., 2018). El montaje experimental es el mismo en las dos experiencias, con solo variaciones en la cohesión del cuerpo inserto en el paquete granular, establecidas mediante la proporción de gelatina (baja o alta) utilizada en cada caso. El paquete granular consiste en una secuencia de $3,3 \mathrm{~cm}$ de espesor total, conformada por una alternancia de capas blancas y negras de arena de cuarzo que abarca un área no confinada de 55 por $45 \mathrm{~cm}$ (Fig. 2). Las dimensiones del modelo no intentan representar un prototipo en 
TABLA 2. PARÁMETROS DEL ESCALAMIENTO UTILIZADO EN LOS MODELOS ANÁLOGOS.

\begin{tabular}{|c|c|c|c|c|c|}
\hline $\begin{array}{l}\text { Parámetros de } \\
\text { escalamiento }\end{array}$ & $\mathbf{L}(\mathbf{m})$ & $\mathrm{g}\left(\mathrm{m} / \mathrm{s}^{2}\right)$ & Co (Pa) & $\mathbf{V}(\mathbf{m} / \mathbf{s})$ & $\mathrm{T}(\mathrm{s})$ \\
\hline Naturaleza & $1.000(1 \mathrm{~km})$ & 9,81 & $1,52 \times 10^{8}$ & $7,8 \times 10^{-11}(0,24 \mathrm{~cm} / \mathrm{a})$ & $1,74 \times 10^{14}(5,4 \mathrm{Ma})$ \\
\hline Modelo & $0,01(1 \mathrm{~cm})$ & 9,81 & 1.520 & $2,5 \times 10^{-5}(9 \mathrm{~cm} / \mathrm{h})$ & $5.400(1,5 \mathrm{~h})$ \\
\hline Razón modelo/naturaleza & $10^{-5}$ & 1 & $10^{-5}$ & $3,2 \times 10^{-5}$ & $3,1 \times 10^{-11}$ \\
\hline
\end{tabular}

L: longitud; g: gravedad; Co: cohesión; V: velocidad; T: tiempo.

particular, sino que responden a consideraciones experimentales con el objetivo de minimizar los efectos de borde. Asimismo, se prescindió de muros laterales para evitar perturbaciones producto del roce asociado a la fricción lateral. El cuerpo cohesivo, constituido por la mezcla arena/gelatina, es un cilindro de $9 \mathrm{~cm}$ de diámetro y $2,7 \mathrm{~cm}$ de espesor ubicado en profundidad en el centro del paquete granular. Las dimensiones del cuerpo cohesivo también responden a razones experimentales y están estrechamente relacionadas con las dimensiones del modelo en su conjunto. Dicho cuerpo es cubierto por la última capa del paquete granular, con el objetivo de prevenir diferencias topográficas entre los objetos. Sobre esta última capa, se agregó una fina grilla $5 \times 5 \mathrm{~cm}$ de material oscuro para una mejor visualización de la deformación superficial (Fig. 2). Al igual que el paquete granular, el cuerpo cohesivo también está construido en una alternancia de colores contrastantes, lo que permite visualizar su deformación interna. El arreglo inicial fue sometido a acortamiento ortogonal durante una hora y media, a una velocidad constante de $9 \mathrm{~cm} / \mathrm{h}$, alcanzando un acortamiento total de $13,5 \mathrm{~cm}$. Similar a las dimensiones del modelo, el acortamiento aplicado no busca emular una fase de deformación particular, sino que responde al requisito experimental de que el frente de deformación sobrepase el sector en que se ubica el cuerpo cohesivo. La vista en planta del modelo fue fotografiada a intervalos regulares de tiempo para registrar la evolución superficial de la deformación. Al finalizar las experiencias, los modelos fueron humedecidos para ser seccionados en perfiles paralelos a la dirección de acortamiento y fueron fotografiados para extraer el registro de la deformación interna del sistema en su estado final.

Además de lo anterior, se ha realizado un registro de velocidad de desplazamiento de las partículas a partir de imágenes PIV (Particle Image Velocimetry).
Esta metodología permite determinar un campo de vectores con una técnica de correlación de imágenes (Lourenco, 1991). Se denomina PIV granular a la aplicación de esta técnica sobre materiales comunes en geología como los que se han utilizado en los modelos analógicos de este estudio (arena). El principio general de PIV es iluminar partículas para el trazado de líneas en el campo del desplazamiento de interés, y adquirir dos imágenes del campo del desplazamiento con una separación de tiempo conocida, lo que determina el movimiento de las partículas entre las dos imágenes. Este desplazamiento dividido por la diferencia de tiempo permite obtener el campo de velocidad. El cálculo de la función de correlación cruzada es la etapa fundamental en el análisis de imágenes mediante PIV, y comúnmente se basa en la transformada de Fourier, contenida, generalmente, en los algoritmos computacionales de los códigos que permiten su aplicación a las imágenes que se tratarán. En este estudio se utilizó PIVlab 2.0 (Thielicke y Stamhuis, 2014) mediante el software Matlab.

El objetivo de aplicar PIV a los modelos analógicos es determinar los vectores de desplazamiento que describen la magnitud y la dirección del movimiento de las partículas sobre la superficie del modelo. Para lo anterior, se cuenta con focos de luz que permiten la homogeneización de las imágenes, lo que elimina la variable de los cambios de luz natural debidos a la duración de los experimentos. La captura de datos de los modelos analógicos se realizó mediante la toma de imágenes de los experimentos con una cámara digital desde una vista aérea. Para estas mediciones se utilizaron marcadores visuales (cuadrículas con material de igual composición, pero distinto color) tradicionalmente empleados en este tipo de experimento, que ayudan a la visualización de las deformaciones, pero que no afectan los resultados del análisis. Tras un preprocesamiento de las imágenes (e.g., revisión de contraste entre pares), estas son analizadas en 
pares consecutivos con la técnica de correlación PIV; la imagen se divide en zonas de interrogación y cada zona de la primera imagen es comparada con la misma zona en la segunda imagen. Tras esto, los vectores obtenidos son evaluados a fin de detectar y eliminar anomalías, de acuerdo con la distribución de estos y poniendo un límite en la desviación considerada aceptable (Pérez, 2019).

Las vistas en planta correspondientes a cada etapa de $25 \%$ de acortamiento de cada set de experimentos se compararon con aquellas de los demás sets. Cada etapa ha sido cubierta por una capa de color, cuya escala (tonos fríos a cálidos) representa la magnitud de los vectores de velocidad que el software rescata para cada sector del modelo en las etapas seleccionadas. Los tonos más cálidos (rojos) indican un desplazamiento en el área de 32 píxeles entre un par de imágenes tomadas a 3 minutos de diferencia. Un desplazamiento de 32 píxeles por cuadro representa aproximadamente entre 4,5 a 4,7 $\mathrm{mm}$ dada la escala de los modelos analizados. Esta velocidad queda también caracterizada gráficamente por los vectores (flechas) sobre la imagen, los cuales además muestran la dirección de los desplazamientos locales.

\section{Resultados}

\subsection{Evolución estructural}

El desarrollo de las dos series de experimentos (Co1 y Co2) se analiza a continuación sobre la base de las vistas en planta. Las imágenes captadas a intervalos regulares de 3 minutos son 30 , por lo que se ilustrarán las características más importantes en 4 etapas de su evolución $(25 \%, 50 \%, 75 \%$ y $100 \%)$ del total de acortamiento aplicado $(13,5 \mathrm{~cm}$ para ambas series).

\subsubsection{Serie Co1: cuerpo discordante de cohesión baja}

La primera evidencia de deformación en la serie de experimentos Co1 comenzó a manifestarse a los $0,9 \mathrm{~cm}$ de acortamiento (antes del 25\%, Fig. 3), con la formación de una primera falla inversa (F1) de rumbo aproximado N-S (Fig. 3). Dicha falla se encuentra alrededor de $8 \mathrm{~cm}$ al $\mathrm{E}$ del muro móvil, y no alcanza a aflorar en superficie en el sector donde se ubica el cuerpo cilíndrico. Una segunda falla inversa (F2) se desarrolló entre los 2,2 y 3,2 cm de acortamiento (ver Fig. 3, Co1 a 25\%); ella presenta un rumbo aproximado N-S en sus extremos, pero en el centro adopta una forma cóncava hacia el $\mathrm{E}$ siguiendo la geometría del cuerpo cohesivo, pero sin cortarlo en superficie. Junto con la generación de esta nueva falla, se produjo una flexión en el rumbo de $\mathrm{F} 1$ en su parte central, siguiendo, al igual que F2, la curvatura del cuerpo cohesivo (Fig. 3, a $25 \%$ ). Dado esto, el alzamiento en la zona central genera, en todas las etapas, mayor pendiente que en los extremos, donde las fallas se encuentran más espaciadas entre sí (Fig. 3). Entre los 4 y $5,4 \mathrm{~cm}$ de acortamiento se desarrolló una tercera falla inversa (F3), cuyo rumbo se curva en el centro

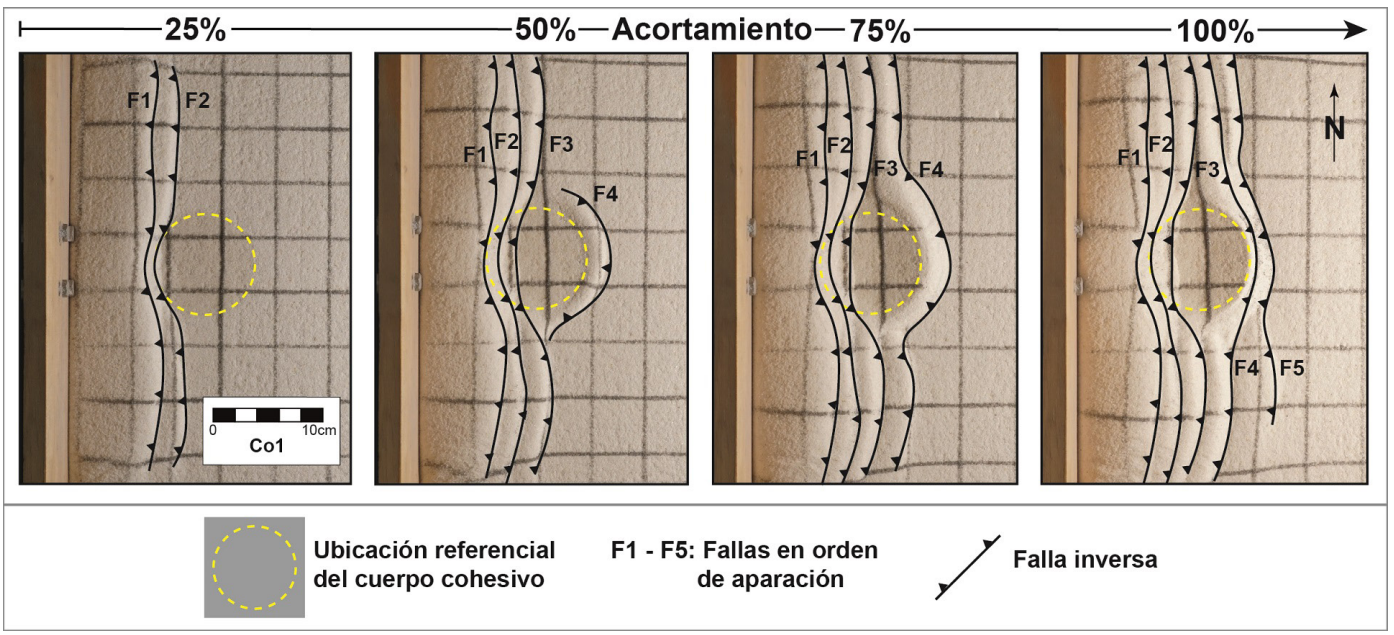

FIG. 3. Vista en planta de la evolución estructural de la serie Co1 para intervalos de $25 \%$ de acortamiento aplicado. 
de la traza adaptando la geometría circular del cuerpo y emplazada superficialmente por encima de este último en su zona central (Fig. 3). Casi de manera sincrónica, se evidencia la generación de una incipiente falla inversa (F4) ubicada en el borde E del cuerpo cilíndrico, cuyo rumbo varía siguiendo la geometría circular del cuerpo.

A los 6,8 cm de acortamiento (50\% en Fig. 3), la falla F4 se muestra bien desarrollada; a partir de este punto, la deformación inducida por el desplazamiento del muro móvil en la zona central del modelo va a ser trasladada al E de la ubicación referencial del cuerpo cohesivo; como consecuencia de esto, se genera una planicie circular en la zona superficial por encima de dicho cuerpo.

Después de aplicar entre el $50 \%$ y el $75 \%$ de acortamiento, la falla generada en el borde del cuerpo (F4) registra un notable alzamiento en el centro del modelo, lo que origina un aumento de pendiente en el sector, y logra, de ese modo, expandir su traza hacia los extremos del modelo adoptando un rumbo aproximado N-S.

En la última etapa de deformación, con un acortamiento entre 10,5 y 13,5 cm (posterior al $75 \%$ de acortamiento aplicado), se generó la falla inversa (F5) al E del cuerpo cohesivo, la que en el centro toma el rumbo del borde de la circunferencia de dicho cuerpo (Fig. 3 al 100\%). Esta última falla (F5) tiene un comportamiento de rumbo disímil en los extremos del modelo: en su zona $\mathrm{N}$ se muestra bien desarrollada y con poco espaciado respecto a las estructuras previamente formadas, pero en su zona S la estructura no se logra desarrollar hasta los bordes del modelo y mantiene un mayor espaciado en relación con las fallas generadas previamente en el sector.

\subsubsection{Serie Co2: cuerpo discordante de cohesión alta}

El primer indicio de deformación comenzó con la generación de una primera falla inversa de entre los 0,9 y $1,8 \mathrm{~cm}$ de acortamiento (F1 en la Fig. 4). Esta se encuentra a $9 \mathrm{~cm}$ promedio al $\mathrm{E}$ del muro móvil y mantiene un rumbo aproximado N-S. Su traza está emplazada justo en el borde $\mathrm{W}$ de la ubicación referencial del cuerpo cohesivo en la superficie (Fig. 4). Una segunda falla inversa (F2) se generó entre los 2,8 y $3,6 \mathrm{~cm}$ de acortamiento (antes del $25 \%$ de acortamiento aplicado) con un rumbo aproximado $\mathrm{N}-\mathrm{S}$, pero de traza ondulada con su lado cóncavo hacia el E, adaptándose al borde circular del cuerpo cohesivo ubicado en la parte central del modelo (Fig. 4). A medida que avanza el acortamiento, se observa que la traza de F1 se va curvando, con lo cual adopta una geometría similar a F2, de manera que las trazas del par de fallas se mantienen aproximadamente paralelas entre sí; sin embargo, la separación entre ellas es mayor en los extremos que en el centro (Fig. 4 en todas las etapas). F2 aflora por sobre la ubicación referencial del cuerpo cohesivo en superficie, alrededor del borde $\mathrm{W}$ de dicho cuerpo.

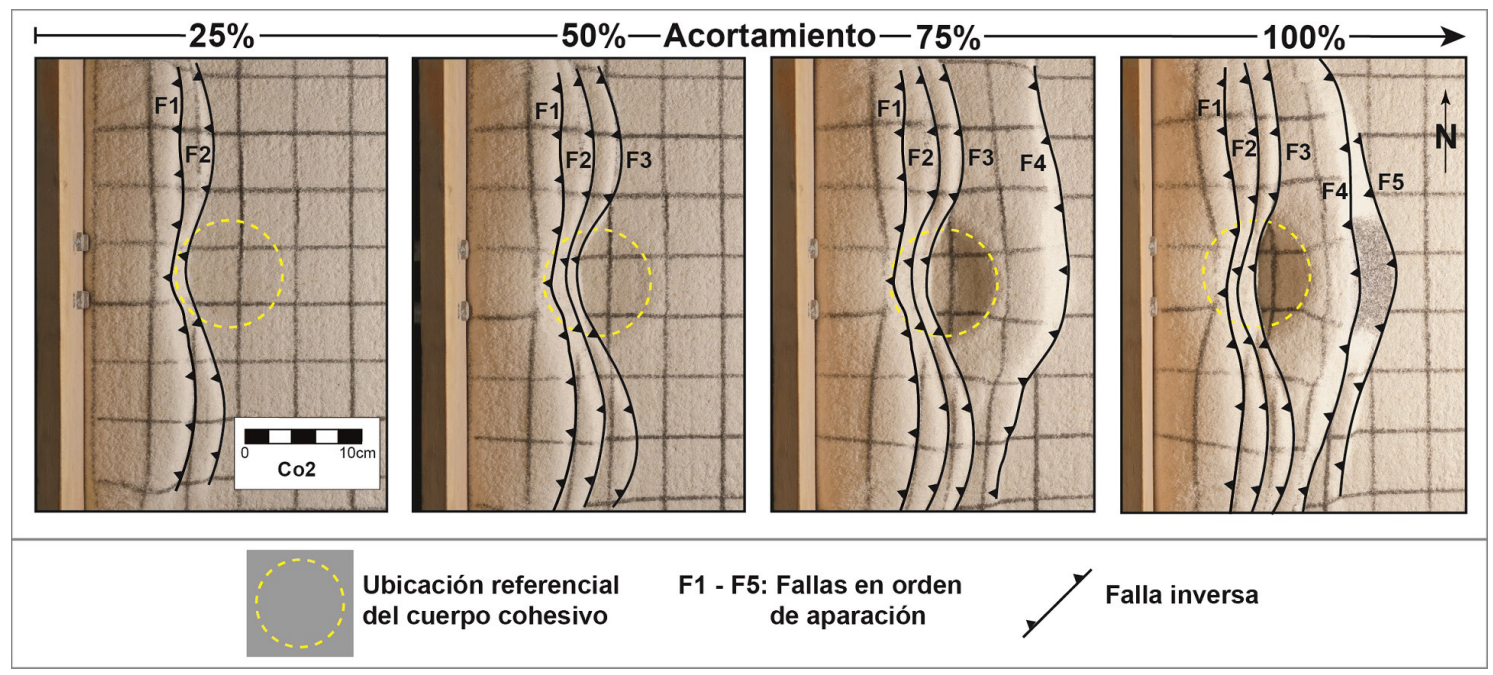

FIG. 4. Vista en planta de la evolución estructural de la serie Co2 para intervalos de $25 \%$ de acortamiento aplicado. 
A los 5,8 cm de acortamiento, aparece bien desarrollada una tercera falla inversa (F3) con un rumbo similar a F2, pero con una curvatura más acentuada, tanto en la parte central (cóncava enfrentando el E) como en sus extremos (convexo enfrentando el E) (Fig. 4 desde 50\% de acortamiento). En relación con esto, el espaciamiento entre el trío de fallas en la zona central es notablemente menor que en los extremos, donde se duplica el distanciamiento entre las estructuras. Esta última falla (F3) se sitúa por sobre la ubicación referencial del cuerpo cohesivo y pasa aproximadamente por el medio de su área superficial en el centro del modelo.

Entre los 7,8 y $9,5 \mathrm{~cm}$ de acortamiento (antes del $75 \%$ de acortamiento aplicado) la deformación superficial se desplazó al E (unos $5 \mathrm{~cm}$ promedio) respecto de la ubicación referencial del cuerpo cohesivo, con el desarrollo de una cuarta falla (F4 en Fig. 4 a $75 \%$ ). Esta falla presenta un rumbo aproximado $\mathrm{N}-\mathrm{S}$ en el centro y $\mathrm{N}$ del modelo, pero en su extremo $\mathrm{S}$ se curva levemente hacia el W. Como consecuencia de lo anterior, F4 muestra una separación cercana a $8 \mathrm{~cm}$ en relación con $\mathrm{F} 3$ en su extremo $\mathrm{N}$; mientras que en su extremo $\mathrm{S}$, esta distancia no sobrepasa los $3 \mathrm{~cm}$. En este punto, se aprecia también una subsidencia en la superficie situada por sobre la ubicación referencial del cuerpo cohesivo, la que tiene una pendiente hacia el $\mathrm{W}$, notoria desde el $75 \%$ de acortamiento aplicado (Fig. 4).

En la etapa final del modelo, entre los 12 y $13,5 \mathrm{~cm}$ de acortamiento, se desarrolló una quinta falla inversa (F5) a $2 \mathrm{~cm}$ al E de F4 (Fig. 4 a 100\%). Esta no logra alcanzar por completo los extremos del modelo, y su rumbo, aproximadamente N-S en el centro, se curva levemente y adquiere una forma convexa hacia el frente de deformación. En este último estadio de la deformación se produce también el afloramiento de una capa interior del paquete granular debido a la actividad de F4. Este material cae por gravedad y se posa en la pendiente generada entre F4 y F5 en la parte central del modelo (Fig. 4 a 100\%).

\subsubsection{Aplicación de Particle Image Velocimetry (PIV) a los modelos analógicos de este estudio}

En la figura 5 se puede observar que la etapa 1 en ambos modelos ( $25 \%$ de acortamiento) es similar en cuanto a que los desplazamientos de material se acumulan en la zona anterior, y con una leve curvatura relacionada con la geometría del cuerpo cohesivo, previo a una próxima etapa de traslado de la deformación hacia la zona colindante a este. Sin embargo, esta curvatura es más pronunciada en el set Co2 (mayor cohesión) (Fig. 5B a 25\%). Esto indica que la velocidad de desplazamiento de material (corrimiento hacia la zona posterior) que producen las primeras fallas generadas, es menor en el set Co1 que en el set Co2; sin embargo, como la cantidad de acortamiento es la misma para ambos sets, este acortamiento (desplazamiento del muro móvil) debe resolverse de otra forma en el modelo Col, ya sea a modo de mayor alzamiento o con la generación de fallas fuera de secuencia o retrocorrimientos. De la imagen PIV de este modelo (Fig. 5A a 25\%), es posible ver que incluso en esta etapa el material ya se estaba desplazando por sobre la zona donde en profundidad se indica la presencia referencial del cuerpo cohesivo (Fig. 3), aun cuando las series de fotografías no permiten visualizar esta deformación por no aflorar aún una falla en superficie.

Desde la segunda etapa seleccionada para visualizar la evolución en planta ( $50 \%$ de acortamiento) son aún más evidentes las diferencias en ambos sets. Al $50 \%$ de acortamiento (Fig. 5) el set Co1 muestra que el desplazamiento afecta toda la región anterior al cuerpo cohesivo, y este es trasladado en bloque, con límites claros, en relación con el material ubicado colindante al $\mathrm{N}$ y S de este, y en la zona posterior, cuyos colores fríos son indicativos de cierta "quietud" en esta etapa. Esto es muy distinto a la situación que ocurre para el set $\mathrm{Co} 2$, donde las mayores velocidades de desplazamientos (tonos cálidos en Fig. 5B a 50\%) ocurren en la zona anterior y colindantes al $\mathrm{N}$ y S del cuerpo. La zona referencial ubicada sobre el cuerpo cohesivo se desplaza hacia la región posterior (tonos amarillos a celestes), la cual presenta deformación en una región mayor que para el caso del set Col en esta etapa, pero con una menor magnitud y límites menos claros.

En la etapa siguiente (75\% en Fig. 5) el set Co1 continúa con un patrón similar a la etapa anterior; se observan con claridad los límites del cuerpo cohesivo, dado que los desplazamientos de material se concentran en la zona anterior y sobre este último; la diferencia con la etapa previa es que la deformación ha avanzado hacia la región posterior en las zonas colindantes al $\mathrm{N}$ y $\mathrm{S}$ del cuerpo cohesivo (Fig. 5A a 50\% y 75\%). Para el set $\mathrm{Co} 2$, se observa, en cambio, que al $75 \%$ de acortamiento la evolución en planta ha generado una notoria diferencia, tanto con el 50\% del mismo 


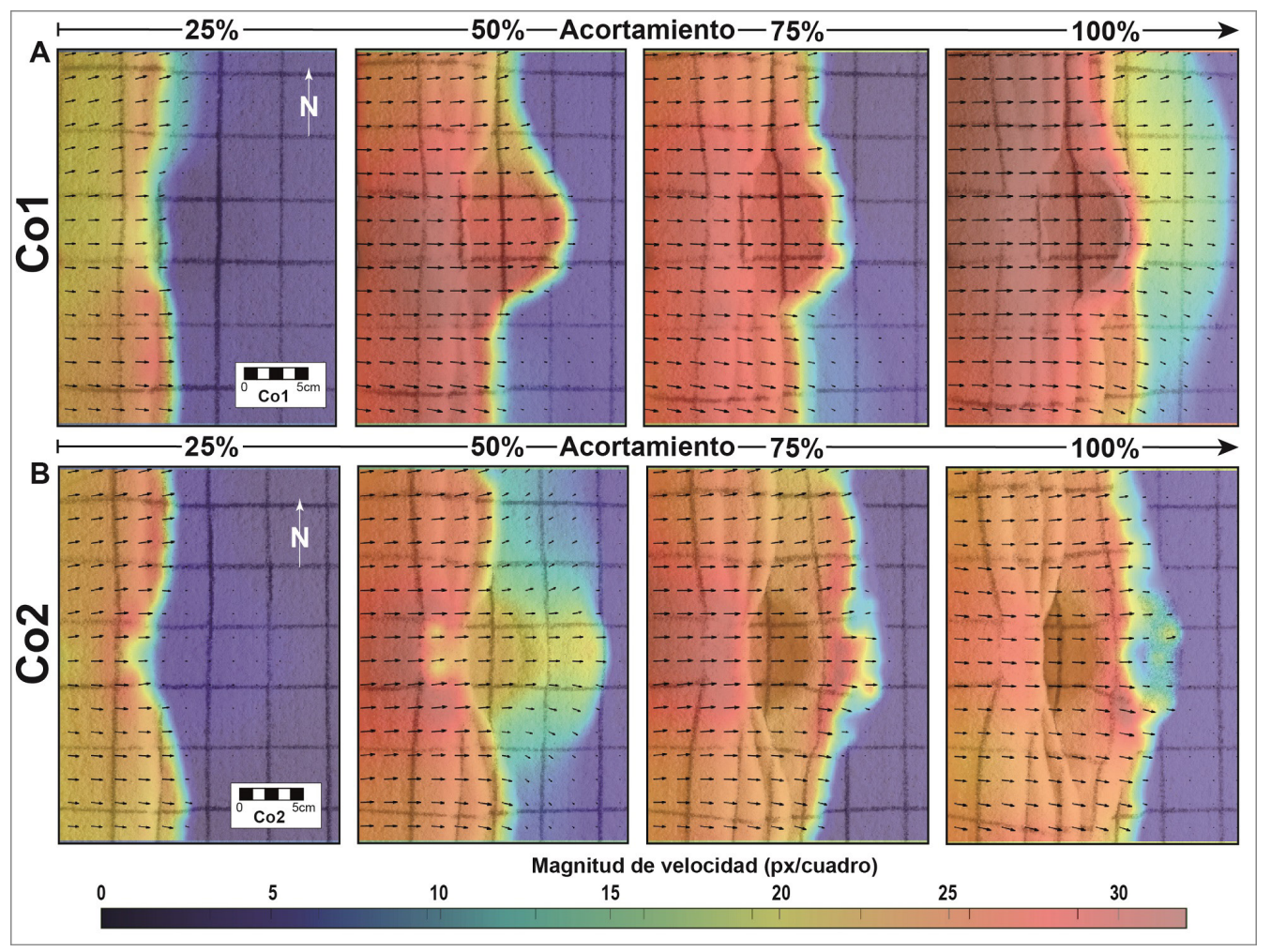

FIG. 5. Análisis PIV de la evolución en planta de ambos sets de modelos $(\mathrm{A}=\operatorname{set} \mathrm{Co} 1$, y $\mathrm{B}=$ set $\mathrm{Co} 2)$. Los vectores representan dirección y magnitud de la velocidad de desplazamiento (separación) entre dos puntos inicialmente contiguos en la etapa observada; la escala de color permite visualizar la magnitud de velocidad (barra inferior, px/cuadro) de estos vectores superficiales para su mejor comparación.

modelo como con la misma etapa para el set Co1 (Fig. 5). La mayor velocidad de desplazamiento se ubica en la zona posterior y traspasa la ubicación referencial del cuerpo cohesivo, lo que genera un frente de deformación activo cercano al límite este del área procesada (Fig. 5B a 75\% y 100\%). La mayor actividad (magnitud de velocidad de desplazamiento en tonos cálidos) se concentra en este nuevo frente de deformación y en la zona anterior y colindante al cuerpo cohesivo; toda la región, al N y S de estas zonas, y sobre la ubicación referencial del cuerpo cohesivo, tiene un desplazamiento homogéneo, pero en una magnitud de velocidad menor (tono anaranjado) que en las otras dos zonas activas (Fig. 5B a 75\%).

En la última etapa de modelado (100\% en Fig. 5) el set Co2 mantiene el patrón descrito para la etapa previa, con una leve disminución en la actividad de la zona anterior, y un sutil aumento de la actividad y desplazamiento de la zona posterior. Por otra parte, el set Co1 disminuye levemente la magnitud de desplazamientos en la región que estuvo más activa desde el 50\% del modelado (Fig. 5A); en esta última etapa (100\% en Fig. 5A), la deformación ha avanzado hacia la zona posterior del cuerpo cohesivo (tonos amarillos y celestes), pero no alcanza una actividad tan importante como en la zona que lo limita (tonos rojos).

Respecto al comportamiento de los vectores, se puede observar el cambio de dirección de estos en presencia del cuerpo cohesivo. En ambos sets, los vectores tienden a desviarse desde el centro hacia los extremos en sentido opuesto, lo que produce una imagen especular entre los sectores $\mathrm{N}$ y $\mathrm{S}$ en cuanto a las direcciones vectoriales (Fig. 5). Este fenómeno es mucho más pronunciado en Co2 (mayor cohesión), donde los vectores alcanzan, en algunos casos, la perpendicularidad con respecto a la geometría del cuerpo (Fig. 5B a 50\%). 


\subsection{Resultados observados en sección y síntesis comparativa}

\subsubsection{Estado estructural final series Co1 y Co2}

A modo de síntesis, los rasgos estructurales principales de la serie Co1 (Fig. 6A) corresponden a cinco fallas inversas en secuencia, cuyos rumbos se acomodan a la geometría circular del cuerpo cohesivo, dependiendo de la ubicación y proximidad que guarden con este último. En la vista en sección, es posible notar que las fallas (F1 a F5) tienen una relación espacial similar en las zonas alejadas del cuerpo cohesivo, en donde el espaciamiento entre ellas (Fig. 6A, I) es aproximadamente constante, mientras que cerca del cuerpo cohesivo las estructuras tienden a acercarse o alejarse, dependiendo de si se encuentran en la zona anterior o posterior del modelo. En relación con esto, las fallas en sus sectores extremos ( $\mathrm{N}$ y S) se comportan de manera relativamente similar con un rumbo aproximado N-S. Pero en el sector central, las tres primeras fallas (F1, F2 y F3) presentan un rumbo curvo cóncavo hacia el $\mathrm{E}$ del modelo y las dos últimas (F4 y F5) evidencian una curvatura contraria en su rumbo, convexo hacia el E (Fig. 6A); en otras palabras, vistos en planta, ambos sets estructurales tienden a rodear el cuerpo y generar un espaciamiento menor entre estructuras de un mismo set, pero un espaciamiento mayor entre ambos sets estructurales (anterior o posterior).

En la sección estructural (perfil) que atraviesa el centro de la serie Co1 (Fig. 6A, II), se puede observar el comportamiento en profundidad de las fallas en relación con el cuerpo cohesivo. Las fallas desarrolladas en la zona anterior (F1, F2 y F3) se

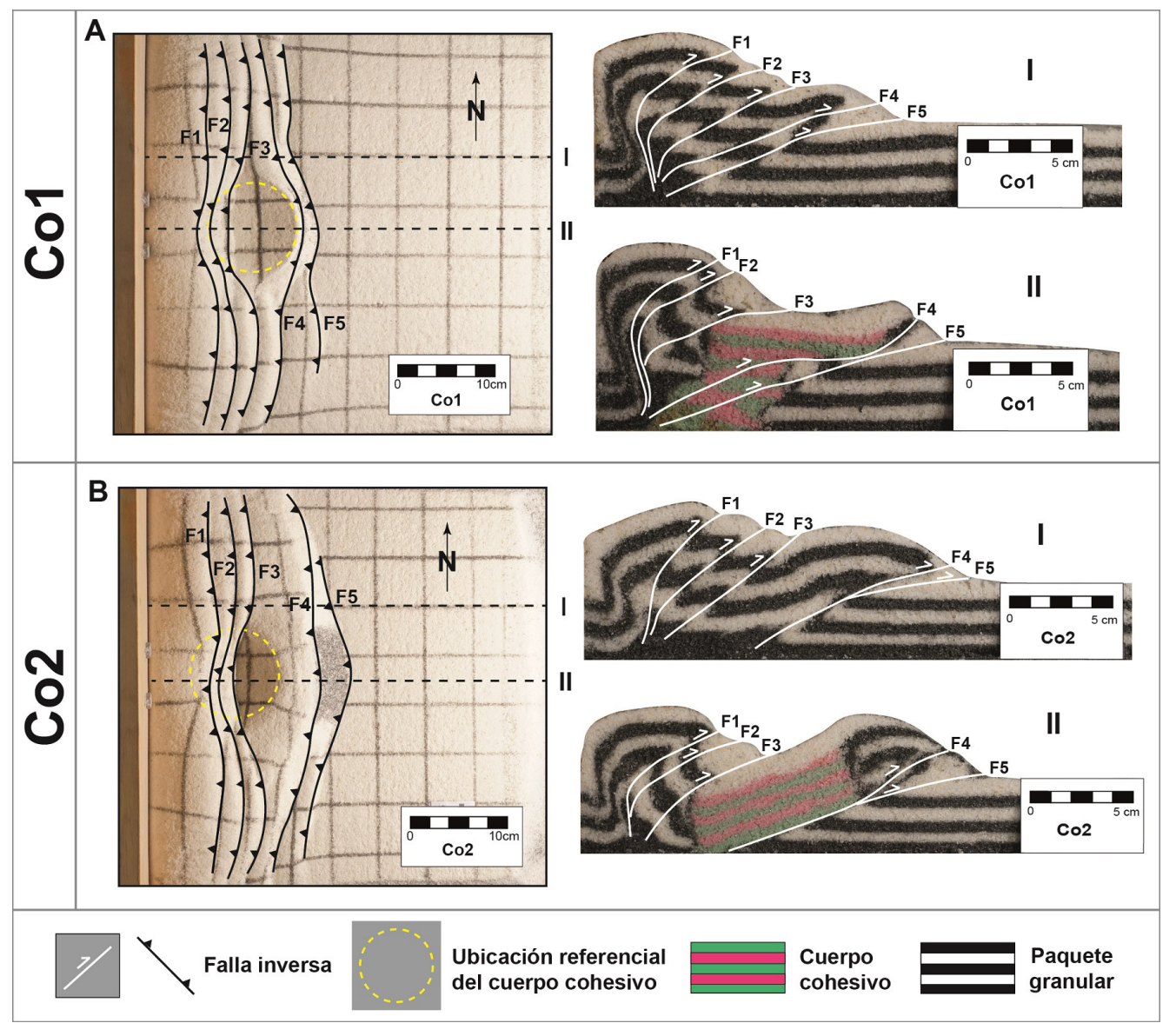

FIG. 6. Vista en planta de estado final para ambas series (A) Co1 y (B) Co2, y sus respectivos perfiles E-W, cuyas trazas atraviesan (I) o no (II) la ubicación del cuerpo cohesivo. 
pliegan y generan un importante alzamiento de la zona anterior, pero no alcanzan a desplazar material del cuerpo cohesivo. En cambio, las de la zona posterior (F4, F5) se comportan como corrimientos en secuencia, que cortan y desplazan parte del cuerpo cohesivo hacia el frente de deformación (zona posterior), fallándolo en profundidad, con menor alzamiento que en la zona anterior y traslación del material mediante despegues de menor inclinación. En síntesis, si bien en la vista en planta (Fig. 6A) las estructuras del set anterior parecen "cortar" el cuerpo cohesivo, el perfil demuestra que es una situación aparente, dada por el traslape de material que generan estas estructuras (Fig. 6A, II); mientras que las estructuras del set posterior, que en planta no atraviesan el cuerpo cohesivo, sí lo cortan en profundidad y afloran una vez que lo han traspasado (Fig. 6A, II).

Los rasgos estructurales principales de la serie $\mathrm{Co} 2$ (Fig. 6B) corresponden a cinco fallas inversas en secuencia, de rumbo aproximado N-S con leves curvaturas según la cercanía con la ubicación referencial del cuerpo cohesivo. Alrededor del centro del modelo se observan dos zonas alzadas, separadas por el cuerpo cohesivo y que, a su vez, dividen en dos sets las fallas generadas en la deformación (Fig. 6B). El primer set estructural, está conformado por las tres primeras fallas inversas (F1, F2 y F3). Estas se encuentran en la zona anterior del modelo (Fig. 6B) y generan un alzamiento algo menor que las del set anterior del modelo Co1 (Fig. 6A y B, II). Estas estructuras nacen en profundidad al $\mathrm{W}$ del cuerpo cohesivo y afloran por sobre la capa superficial que lo recubre. Sus trazas son relativamente paralelas entre sí con un rumbo curvo y cóncavo hacia el $\mathrm{E}$ en el centro. A medida que los perfiles se acercan al centro, se observa que las fallas (F1, F2 y F3) se aproximan entre sí, es decir, el espaciamiento entre estructuras de un mismo set es mayor en las lejanías del cuerpo cohesivo. La estructura F3 cabalga por encima del cuerpo y de la capa superficial que lo cubre, lo que ocasiona que, tanto esta estructura como F2 y F1, afloren por sobre el trazado del cuerpo cohesivo en la vista en planta (Fig. 6B), pero sin fallarlo (Fig. 6B, II).

Un segundo set (posterior) está conformado por las fallas F4 y F5, las que nacen en profundidad por debajo del cuerpo cohesivo y afloran al E del mismo (Fig. 6B, II), es decir, transportan tectónicamente todo el cuerpo cohesivo hacia la zona posterior, pero sin fallarlo. El par de fallas tiene un rumbo aproximado $\mathrm{N}-\mathrm{S}$ con una leve curvatura convexa hacia el E, que es más pronunciada en F5. A diferencia del set anterior (Fig. 6B), el espaciamiento entre el par de fallas es mayor en el centro que en los extremos, característica que diferencia a esta serie (modelo $\mathrm{Co} 2)$ de lo observado en el modelo anterior (Co1), para la cual el set posterior tenía la misma relación de espaciamiento que el set anterior. En el sector central del modelo Co2 y más próximo al cuerpo cohesivo, los perfiles muestran que ambas fallas (F4 y F5) se ramifican desde un plano compartido, el que nace por debajo del cuerpo cohesivo y lo desplaza intacto por encima del paquete granular hacia el E del modelo. Esto hace que el cuerpo se incline hacia el $\mathrm{W}$ a medida que se cabalga a lo largo del plano de falla (Fig. 6B, II). El alzamiento que generan ambos sets es similar (Fig. 6B, II), y deja una depresión con forma de "V" entre los dos, característica que también lo diferencia del modelo Col (Fig. 6 A y B, II).

\subsubsection{Síntesis comparativa entre ambas series (Co1 y Co2)}

Los rasgos comunes en ambos modelos corresponden a cinco fallas inversas en secuencia y de vergencia hacia la zona posterior. A su vez, se repite la distribución de dichas estructuras, con tres de estas ubicadas en la zona anterior y dos en el sector posterior (Tabla 3). En las dos series de modelación, el primer set de estructuras forma láminas de material de la zona anterior que cabalgan por sobre el cuerpo cohesivo, enterrándolo en parte. La zona de deformación en las inmediaciones del cuerpo cohesivo presenta un ensanchamiento notable, rasgo que se va perdiendo gradualmente hacia los extremos ( $\mathrm{N}$ y S ) del modelo. La geometría general del material deformado adopta la forma de una cuña con pendiente hacia la zona posterior, la que es interrumpida en la parte central de ambos modelos por la presencia en profundidad del cuerpo cohesivo (Fig. 6A y B, II). Este último actúa como un obstáculo que genera una desviación en la típica geometría triangular de una faja plegada y corrida.

Por otro lado, la diferencia de cohesión entre los cuerpos de ambas series $\mathrm{Co} 1$ y $\mathrm{Co} 2$, genera diferencias notorias en la distribución superficial de los sets estructurales como también en su comportamiento en profundidad y en la geometría general del material deformado. Existen disimilitudes 
TABLA 3. CUADRO RESUMEN DE SÍNTESIS COMPARATIVA ENTRE SERIES CO1 Y CO2 EN SU ESTADO FINAL.

\begin{tabular}{|c|c|c|c|}
\hline \multicolumn{2}{|c|}{ Cohesión cuerpo } & Baja & Alta \\
\hline \multicolumn{2}{|r|}{ Código } & Co1 & $\mathrm{Co2}$ \\
\hline \multirow[t]{5}{*}{ Fallas en secuencia } & Cantidad & 5 & 5 \\
\hline & $\begin{array}{c}\text { Aparición en la superficie ( } \mathrm{cm} \text { de } \\
\text { acortamiento) }\end{array}$ & $\begin{array}{c}\text { F1 }(1,8), F 2(3,2), F 3(5,4), F 4 \\
(9,8) \text { y F5 }(13,5)\end{array}$ & $\begin{array}{c}\text { F1 }(1,8), \text { F2 }(3,6), F 3(5,8), F 4 \\
(9,5) \text { y F5 }(13,5)\end{array}$ \\
\hline & Cortan el cuerpo & 2 & - \\
\hline & Rumbo N-S & 5 & 3 \\
\hline & Rumbo convexo & - & 2 \\
\hline \multirow[t]{2}{*}{ Zona anterior } & Alzamiento máx. (cm) & 9,1 & 8,6 \\
\hline & Fallas & 3 & 3 \\
\hline \multirow[t]{2}{*}{ Zona posterior } & Alzamiento máx. (cm) & 6,1 & 6,9 \\
\hline & Fallas & 2 & 2 \\
\hline \multicolumn{2}{|c|}{ Alcance E-W (cm) } & 17,9 & 20,5 \\
\hline
\end{tabular}

entre el espaciamiento de las estructuras, tanto a nivel individual como entre la ubicación de cada set estructural. La serie Col presenta un espaciamiento individual entre las estructuras relativamente constante (4 $\mathrm{cm}$ aprox.). En cambio, la serie $\mathrm{Co} 2$ revela una relación inversa entre el set anterior, donde el espaciamiento individual de las estructuras en el sector central (aledaño al cuerpo) es menor que el de los extremos N y S. Lo opuesto ocurre con el set estructural posterior en la misma serie. Asimismo, el espaciamiento entre ambos sets estructurales (anterior y posterior) es mayor en Co2.

El alzamiento generado por ambos sets de estructuras también muestra una relación inversa al comparar ambas series. Por un lado, el set anterior produce un alzamiento mayor en $\mathrm{Co} 1$ que en $\mathrm{Co} 2 \mathrm{y}$, por el otro, el set posterior causa un alzamiento mayor en Co2 que en Co1 (Tabla 3). Esto está relacionado con el alcance (distancia máxima) de la deformación hacia la zona posterior, el cual es menor en Col debido a que el primer set de estructuras absorbe la mayor parte de la deformación y deja con pobre desarrollo al set posterior; mientras que en $\mathrm{Co} 2$, ambos sets estructurales logran un desarrollo similar $\mathrm{y}$, por tanto, extendiendo la deformación hacia zonas más alejadas del muro móvil. A causa de esto, se evidencia también una diferencia en la pendiente entre las cuñas de material de ambas series en los sectores donde no hay presencia del cuerpo cohesivo, donde Co1 muestra una pendiente de mayor inclinación que $\mathrm{Co} 2$ (Fig. 6A y B, I).

Otra diferencia importante entre ambas series corresponde al área de perturbación que origina la presencia del cuerpo cohesivo en sus sectores aledaños. El efecto del cuerpo cohesivo en Co1 es casi imperceptible a un par de centímetros hacia el $\mathrm{N}$ o S, mientras que en $\mathrm{Co} 2$ el efecto es evidente casi hasta los límites N y S del modelo (Fig. 6A y B, I).

Una de las diferencias más evidentes en los perfiles de ambas series es el desarrollo de las estructuras del set posterior. En Co1 las dos fallas (F4 y F5) cortan el cuerpo cohesivo atravesándolo de un lado a otro y afloran en la zona posterior del modelo (Tabla 3). En Co2 el cuerpo cohesivo no es fallado, sino que es transportado hacia el frente de deformación producto de un nivel de despegue común que se bifurca en las dos fallas que conforman el set estructural posterior. Al ser transportado sobre el bloque colgante del 
nivel de despegue, el cuerpo es rotado, aumentando el manteo de su techo hacia el oeste y, por lo tanto, la pendiente de la superficie. En Co1, si bien se genera una zona "baja" en relación con las zonas alzadas afectadas por los sets estructurales, el cuerpo mantiene su relación inicial sin inclinación. Debido a la ramificación posterior del nivel de despegue que transporta el cuerpo, en Co2 solo se observan 4 fallas inversas en profundidad (Fig. 6 B, I y II), mientras que en Co1, tanto en superficie como en profundidad, se observan las cinco fallas individuales (Fig. 6 A).

\section{Discusión}

Los experimentos reportados en este estudio en relación con la deformación contraccional de un paquete granular que incluye un cuerpo discordante de mayor cohesión que el entorno, generaron una cuña de acreción constituida por una secuencia de fallas imbricadas tal como los resultados reportados por Mulugeta y Koyi (1987, 1992), Mulugeta (1988), Huiqi et al. (1992) y Gomes (2013), entre otros. A medida que progresa la deformación, el material acoplado en la parte inferior o pie de la cuña induce la deformación al interior de esta, lo que establece una secuencia de paquetes limitados por despegues de fallas que preservan la deformación dentro de la cuña (Fig. 7) (Davis et al., 1983). Las imbricaciones antiguas rotan hacia atrás y aumentan su inclinación, tal como ha sido planteado en cordones montañosos y cuñas de acreción (e.g., Karig, 1974; Moore y Karig, 1976). A pesar de que el avance del muro móvil es constante, las fallas imbricadas se propagan de manera episódica durante el progreso de la deformación (Mulugeta y Koyi, 1992). Cuando la deformación se extiende hasta el sector donde se encuentra el cuerpo cohesivo, independientemente de que en profundidad este sea cortado o no, el frente de deformación tiende a migrar hacia la zona posterior y a saltar hacia el oriente del cuerpo, con lo cual se genera una segunda cuña, que se configura de la misma forma que la anterior. Según esto, el cuerpo cohesivo actúa como un verdadero muro móvil o backstop, transfiriendo hacia adelante la zona activa de acortamiento. En primera instancia, la deformación compresiva es originada por un límite artificial, mediante el desplazamiento constante del muro móvil. Sin embargo, la deformación provocada por la presencia del cuerpo cohesivo puede representar una adecuada aproximación a las cuñas naturales, en las que los backstop muestran diversas geometrías determinadas por la existencia de regiones más competentes producto de la litificación, de tasas de enfriamiento o del metamorfismo (para el caso de cuñas de acreción). Esto tiene importantes implicancias en la distribución de zonas sismogénicas (Silver et al., 1985; Byrne y Hibbard, 1987; Byrne et al., 1988; Mulugeta y Koyi, 1992).

Una de las características importantes de los resultados de la modelación corresponde a la tendencia de las fallas de evitar al cuerpo cohesivo adoptando sus trazas superficiales la geometría de los bordes de dicho cuerpo. Esta característica es comparable con los resultados de los experimentos elaborados por Marques y Cobbold (2002), en los que se investigó el efecto de la topografía en el desarrollo de cinturones montañosos arqueados.

En relación con lo anterior, modelos compresivos con topografía inicial de meseta o montañas cónicas, localmente mayores que el entorno, tienden a resistir el acortamiento, tal cual lo predice la teoría de la cuña crítica (Davis et al., 1983). En estos casos las fallas
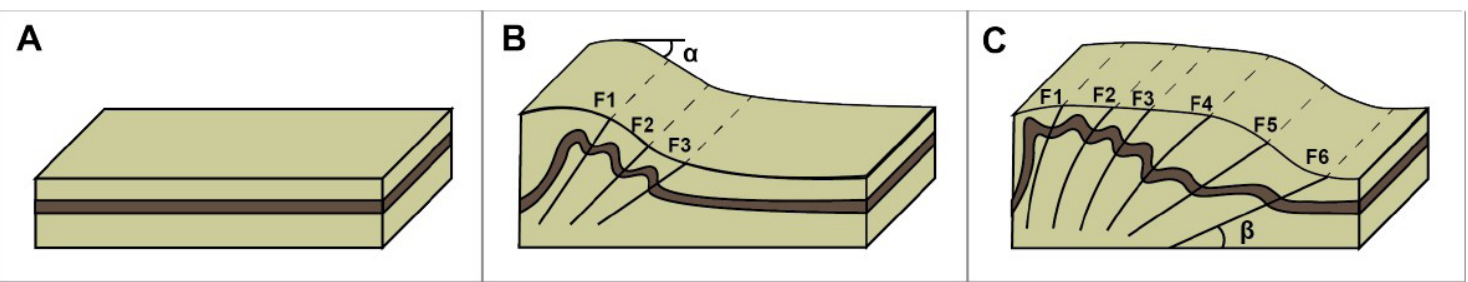

FIG. 7. Esquema conceptual de la evolución interna de una cuña de acreción. A. Paquete granular horizontal, previo al inicio de la deformación; B. Estado intermedio de la deformación: a medida que se alza la cuña y llega al ángulo crítico, esta se deforma internamente, lo que genera una imbricación de fallas en secuencia; C. Estado avanzado de deformación: las imbricaciones antiguas rotan hacia la zona de empuje. $\alpha$ corresponde al ángulo de pendiente del frente de la cuña y $\beta$ es el manteo de las fallas inversas, este último aumenta a medida que progresa la deformación (Modificado de Mulugeta y Koyi, 1992). 
tienden a desarrollarse detrás o delante de estas áreas y con trazas arqueadas en vista en planta (Marques y Cobbold, 2002) (Fig. 8A y B.1). Esta geometría arqueada corresponde, al igual que en los modelos de este estudio, a la geometría del objeto contrastante inserto en el paquete granular.

\subsection{Síntesis respecto del rol de la cohesión}

De ambas series de modelos, en los cuales el único factor que se varió fue la cohesión del cuerpo discordante inserto en las capas de la FPC, podemos interpretar que la configuración estructural resultante, tras un proceso de deformación por compresión, es altamente susceptible a los contrastes de competencia entre los componentes que integran el sistema. Cuando la cohesión del cuerpo insertado es baja y, por tanto, cercana a la del paquete granular que lo contiene, se obtiene una secuencia normal de fallas imbricadas que incluso logran cortar en profundidad a dicho cuerpo. Esto es similar al caso en que no tenemos contraste de competencia alguno, como en la mayor parte de los modelos analógicos compresivos de la literatura (Mulugeta, 1988; Graveleau et al., 2012;
Buiter, 2012). La incidencia del cuerpo de menor cohesión (Co1) se evidencia a través de dos hechos: (1) el patrón adoptado por las trazas superficiales de las fallas se acomoda a la geometría del cuerpo cohesivo, y (2) el avance del patrón estructural hacia la zona posterior, el cual queda de manifiesto por un mayor espaciamiento y escasa elevación en la zona donde este se ubica en profundidad, en desmedro de un alzamiento importante generado por las estructuras en las zonas alejadas del cuerpo. Por otra parte, cuando la cohesión del cuerpo es alta y, por tanto, existe un mayor contraste de competencias con el entorno, el patrón normal de fallas se ve interrumpido por la presencia del cuerpo que pareciera actuar como un obstáculo, gatillando la migración de la deformación hacia la zona posterior, donde eventualmente se generará una segunda cuña alzada. Los patrones que debieran permitir reconocer en una faja plegada y corrida la presencia en profundidad de un cuerpo que presenta un fuerte contraste de cohesión con las rocas en que se encuentra emplazado son: (1) una interrupción completa de la secuencia imbricada de fallas, (2) el alzamiento de una segunda cuña, desplazada de la primera y con una elevación cercana a esta.

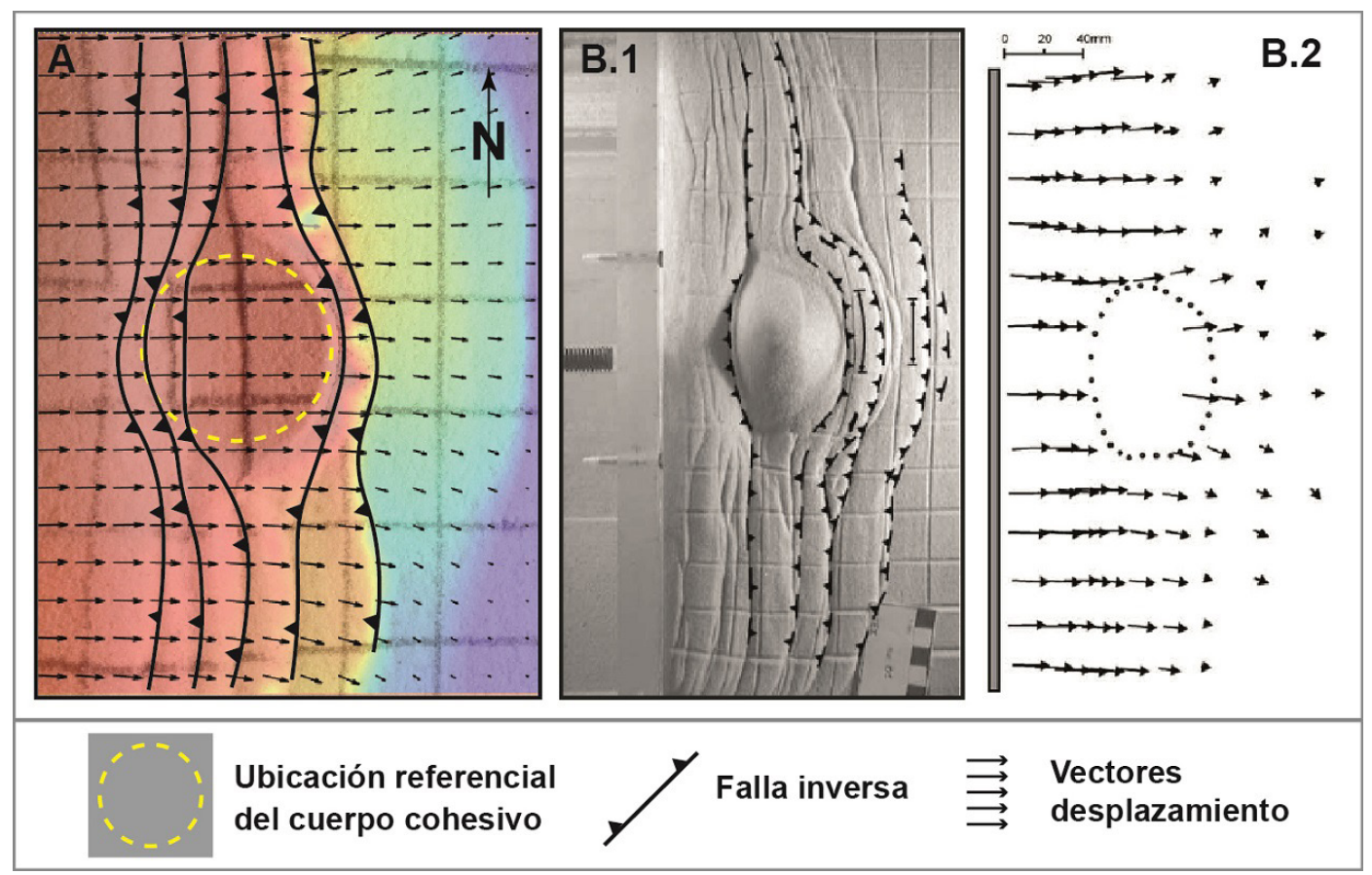

FIG. 8. Comparación con modelo de edificio volcánico. A. Co1; B.1. Modelo 4 modificado de Marques y Cobbold (2002); B.2. Vectores de desplazamiento del modelo 4 (B.1) modificado de Marques y Cobbold (2002). 
La cohesión del cuerpo discordante considerado en los modelos tiene un rol de primer orden en cuanto a la distribución de la deformación a lo largo del modelo. A mayor cohesión, el cuerpo inserto sufre menor deformación interna y es capaz de transmitir el esfuerzo a lo largo del sistema. Esto último es corroborado con modelos numéricos donde se aumenta la cohesión del paquete granular, y a medida que esta crece, la deformación se separa en sistemas imbricados discretos sin deformación interna sustancial (Morgan, 2015). Esto se expresa en los modelos que aquí se presentan, mediante dos sets separados (localizados) de fallas, distanciados por la presencia del cuerpo cohesivo, donde la distribución desplazada de estos sets es mucho más evidente y persistente en los extremos $\mathrm{N}$ y $\mathrm{S}$ para el caso en que la cohesión es mayor (Fig. 6).

\subsection{Contribución del modelado a la interpretación en casos naturales}

El resultado principal que se extrae de este estudio es, en primera instancia, que los patrones estructurales de una zona deformada en compresión pueden estar influenciados por la presencia de cuerpos cohesivos emplazados previamente en las rocas en las que se desarrolla la deformación. A partir de esto, se propone que con un cuidadoso mapeo del patrón estructural de una región se podría inferir la presencia bajo la superficie de cuerpos de mayor cohesión que las rocas de su entorno. Ellos podrían corresponder a bloques de basamento cristalino, ígneo o metamórfico, o a cuerpos plutónicos de alta resistencia a la deformación.

Con el fin de corroborar esta proposición se analiza a continuación la arquitectura de algunas regiones deformadas en compresión, en particular, fajas plegadas y corridas. La comparación entre estos ejemplos naturales y los modelos aquí descritos considerará las semejanzas y las diferencias, tanto en la escala como en la geometría de los patrones estructurales de algunas regiones de la cordillera andina.

Características observadas en este estudio son comparables con los resultados de los experimentos elaborados por Marques y Cobbold (2002) en los que se investiga el efecto de la topografía preorogénica en el desarrollo de cinturones montañosos arqueados. En relación con lo anterior, la resistencia que oponen los cuerpos cohesivos en los modelos de este estudio tiene un efecto semejante a la que oponen los esfuerzos verticales en los modelos de Marques y Cobbold (2002). El patrón radial de los vectores de desplazamiento en la zona posterior del cuerpo cohesivo es otra característica común entre los modelos presentados en este trabajo y los de Marques y Cobbold (2002), lo que corrobora el vínculo entre el efecto de la topografía y el contraste de cohesión sobre la geometría curva del patrón de estructuras generadas en la deformación (Fig. 5 y Fig. 8A y B.2).

Marques y Cobbold (2002) comparan los patrones estructurales arqueados con las tres mesetas más grandes de la Tierra (Tibet, Pamirs y el Altiplano de los Andes centrales) y con el ridge volcánico de Tromen en la Cuenca Neuquina Patagonia norte. En el caso de los Andes centrales, se puede mencionar de manera muy generalizada, que el altiplano se forma como consecuencia de la subducción Andina y que está limitado, tanto al $\mathrm{W}$ como al E, por la Cordillera Occidental y la Cordillera Oriental, respectivamente (Allmendinger et al., 1997). Hacia el S, el altiplano está limitado abruptamente por la zona de transferencia de Tucumán, área de deformación transpresiva (De Urreiztieta et al., 1996) y hacia el $\mathrm{N}$ se curva progresivamente en los Andes peruanos (Fig. 9C). Según evidencia paleomagnética, el antearco chileno se habría comportado rígidamente en el Neógeno (Roperch et al., 2000), con lo cual la deformación migró hacia el oriente de manera episódica y, tal como es sugerido por varios autores, aparentemente el altiplano también habría asumido un comportamiento rígido (Allmendinger et al., 1997; Lamb y Hoke, 1997; Coutand et al., 2001). Marques y Cobbold (2002) sugieren que este comportamiento rígido del altiplano se debe a su alta topografía; en este trabajo se sugiere que además del efecto de la topografía, existiría un contraste de competencias entre los materiales que conforman el altiplano en profundidad y su entorno. Por otra parte, Isacks (1988) menciona que el origen del altiplano es consecuencia de engrosamiento cortical y adición de magma. Además, Perkins et al. (2016) plantea que la adición magmática relacionada con el Cuerpo Magmático Altiplano-Puna contribuye al alzamiento del altiplano, lo cual implicaría la existencia de cuerpos intrusivos en profundidad que podrían aportar esta componente de alta cohesión al sistema.

Otro ejemplo comparable con los modelos analógicos de este trabajo corresponde a la Faja 

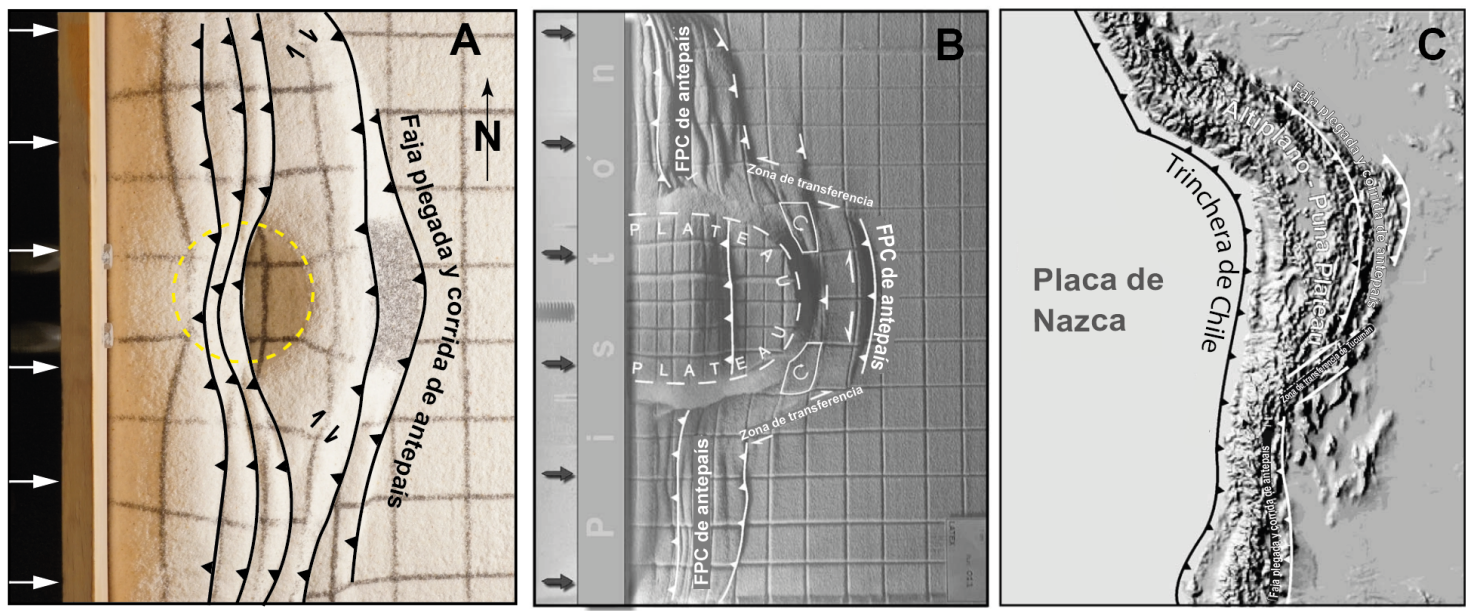

FIG. 9. Comparación entre modelos y el altiplano de los Andes Centrales. A. Co1 en este trabajo; B-C. Comparación entre Modelo 3 de Marques y Cobbold (2002) y los Andes Centrales.

Plegada y Corrida del Aconcagua (FPCA) (Giambiagi et al., 2003). Ella se encuentra en la provincia de Mendoza en Argentina, entre los $32^{\circ} 30^{\prime}$ y los $34^{\circ} \mathrm{S}$, en el sector oriental de la Cordillera Principal andina y cuenta con la cima más elevada de América, el cerro Aconcagua. Este último está conformado por lavas, brechas y cuerpos subvolcánicos andesíticos y dacíticos correspondientes al Complejo Volcánico Aconcagua (Ramos et al., 1996). Estas rocas son cortadas en su parte oriental por la Falla Penitentes, la cual sería responsable del alzamiento del Aconcagua, mientras que la deformación al sur de este es del tipo piel delgada (Ramos, 1985). Las estructuras características de esta deformación epidérmica son las fallas inversas de Las Leñas, Quebrada Blanca, La Yesera y De Navarro (Fig. 10), entre otras, que afectan a rocas de las formaciones Tordillo, Diamante, Agrio y Auquilco, todas sedimentarias y la última conformada por niveles de yeso; ninguna de estas fallas cortaría las rocas del Complejo Volcánico Aconcagua (Ramos, 1985; Ramos et al., 1996) (Fig. 10). La tendencia de la mayoría de las fallas mencionadas de no cortar las rocas del Complejo Volcánico Aconcagua y concentrarse al sur de estas corresponde a una característica comparable a los modelos analógicos desarrollados en este estudio. En este sentido, las rocas del Complejo Volcánico Aconcagua representarían un cuerpo de mayor cohesión y de comportamiento cuasirrígido, contrastado con los niveles sedimentarios que representarían al paquete granular fallado. Sin embargo, esto también podría ser el resultado de una componente topográfica, en relación con los modelos de Marques y Cobbold (2002). En este caso los estudios locales deben considerar, además, la edad relativa de las estructuras y del cuerpo en cuestión, dado que no se descarta que algunas fallas antiguas (previas al cuerpo cohesivo) estén cubiertas por las rocas ígneas o correspondan incluso a las estructuras que facilitaron su emplazamiento.

\section{Conclusiones}

La geometría que adoptan las fallas en los modelos analógicos aquí presentados está íntimamente ligada a la presencia de un cuerpo cohesivo inserto en la sucesión estratificada. Esto es: 1. El patrón geométrico de las fallas presenta curvaturas controladas por la presencia del cuerpo cohesivo, 2. Separación entre sets de estructuras, 3. Las flexuras en el rumbo de las fallas se mantienen aun cuando estas no corten el cuerpo cohesivo o se presenten en zonas colindantes.

Los resultados de la modelación de este trabajo sugieren que:

1. La presencia de un cuerpo de mayor cohesión que el entorno (más resistente a la deformación frágil), afecta el patrón estructural de una faja plegada y corrida, tanto en su secuencia de deformación (temporalidad en la evolución) como en su geometría. 


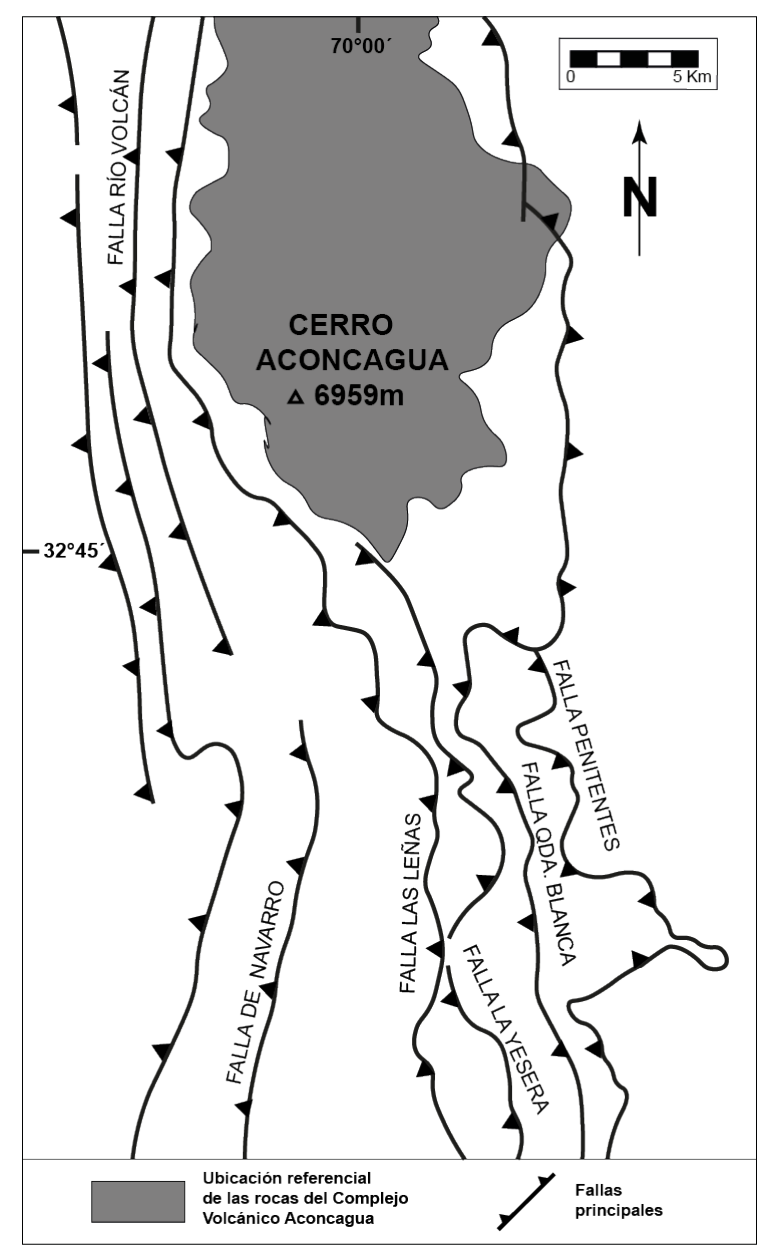

FIG. 10. Distribución esquemática de las trazas de las fallas mayores en la Cordillera Principal oriental, región del Aconcagua, en relación con las rocas del Complejo Volcánico Aconcagua (Ver texto). Modificado de Ramos et al. (1996).

2. La secuencia normal del modelo de cuña crítica se ve afectada por la presencia de cuerpos de cohesión diferente a la secuencia estratificada que lo contiene, por lo que el frente de deformación se desplaza hacia la zona posterior de los cuerpos.

3. Leves diferencias en la cohesión entre dos materiales rocosos en un sistema compresivo genera notorias diferencias en el patrón estructural, tales como espaciamiento entre fallas, geometría de trazas y la posibilidad de que las fallas corten el cuerpo en profundidad para el caso de cohesiones más bajas.

4. Aun cuando el material cohesivo sea deformable, las estructuras tienen la tendencia a evitarlo, trasladando el frente de deformación en la dirección de la vergencia de esta. A mayor contraste de cohesión, la deformación progresará, se alejará del cuerpo cohesivo y generará una región más amplia afectada por la faja plegada y corrida, pero de menor alzamiento en esta zona.En ambos casos, el mayor alzamiento se produce en la zona anterior, previo al encuentro del frente de deformación con el cuerpo cohesivo, es decir, estos cuerpos generan un "contrafuerte" (backstop) que se opone a su avance hasta un punto crítico en que la resistencia ejercida por el cuerpo cede. En algunos casos el cuerpo cohesivo es fallado, y en otros es trasladado en el sentido de la deformación, hasta la generación de un nuevo frente de corrimientos. 
5. Los patrones de fallas generados en las modelaciones realizadas son reconocidos a diferentes escalas espaciales al ser comparados con casos naturales donde existe un contraste de competencias entre cuerpos de mayor cohesión que su entorno. Una de las características similares de los modelos con los prototipos naturales es la tendencia de las fallas a evitar el cuerpo cohesivo y a adoptar en su rumbo la geometría del borde de dicho cuerpo. Se sugiere considerar la presencia de cuerpos más resistentes que su entorno para explicar curvaturas en patrones estructurales naturales (como fajas plegadas y corridas u orógenos).

Finalmente, los resultados de este estudio muestran que los patrones de deformación resultantes de la modelación podrían ser utilizados para reconocer la presencia de cuerpos cohesivos, más competentes que las rocas estratificadas del entorno, aun cuando estos no afloren en superficie.

\section{Agradecimientos}

Los autores agradecen al Laboratorio de Modelamiento Físico del Departamento de Ingeniería en Minas de la Universidad de Santiago (J.P. Vargas, director) y al proyecto DICYT051615JM (Jara et al., 2016-2018) que permitió la ejecución de los experimentos presentados en este estudio. Asimismo, agradecen a N. Conejeros, F. Bustos y J. Acevedo del Departamento de Ingeniería Mecánica de la misma universidad por el respaldo entregado respecto al correcto uso del servo motor y driver. Finalmente, hay que destacar la contribución de W. Vivallo y F. Martínez, cuyos comentarios y sugerencias han permitido mejorar considerablemente esta contribución.

\section{Referencias}

Abdollahie Fard, I.; Braathen, A.; Mokhtari, M.; Ahmad Alavi, S. 2006. Interaction of the Zagros Fold-Thrust Belt and the Arabian-type, deep-seated folds in the Abadan Plain and the Dezful Embayment, SW Iran. Petroleum Geoscience 12: 347-362. doi: 10.1144/1354079305-706.

Acevedo, J.; Bustos, F.; Conejeros, N.; Jara, P. 2018. Versatilidad de una mesa para modelos analógicos de deformación a escala geológica. Geoingeniería 1: 8-15.

Acocella, V.; Tibaldi, A. 2005. Dike propagation driven by volcano collapse: a general model tested at Stromboli, Italy. Geophysical Research Letters 32 (8): 1-4. L08308. doi: 10.1029/2004GL022248.
Allmendinger, R.W.; Jordan, T.E.; Kay, S.M.; Isacks, B.L. 1997. The evolution of the Altiplano-Puna plateau of the Central Andes. Annual Review of Earth and Planetary Sciences 25: 139-174.

Álvarez-Marrón, J.; McClay, K.R.; Harambour, S.; Rojas, L.; Skármeta, J. 1993. Geometry and evolution of the frontal part of the Magallanes foreland thrust and fold belt (Vicuna-Area), Tierra del Fuego, Southern Chile. American Association of Petroleum Geologists Bulletin 77: 1904-1921.

Bonnet, C.; Malavieille, J.; Mosar, J. 2007. Interactions between tectonics, erosion, and sedimentation during the recent evolution of the Alpine orogen: analogue modeling insights. Tectonics 26 (6): 1-5. TC6016. doi: 10.1029/2006TC002048.

Bonini, M.; Sani, F.; Antonielli, B. 2012. Basin inversion and contractional reactivation of inherited normal faults: a review based on previous and new experimental models. Tectonophysics 522-523: 55-88. doi: 10.1016/j. tecto.2011.11.014.

Buchanan, P.G.; McClay, K.R. 1991. Sandbox experiments of inverted listric and planar fault systems. Tectonophysics 188: 97-115. doi: 10.1016/0040-1951(91)90317-L.

Buiter, S.J.H. 2012. A review of brittle compressional wedge models. Tectonophysics 530-531: 1-17.

Bureau, D.; Mourgues, R.; Cartwright, J. 2014. Use of a new artificial cohesive material for physical modelling: Application to sandstone intrusions and associated fracture networks. Journal of Structural Geology 66: 223-236.

Byrne, T.; Hibbard, J. 1987. Landward vergence in accretionary prisms: The role of backstop and thermal history. Geology 15: 1163-1167.

Byrne, D.E.; Davis, D.M.; Lynn, R.S. 1988. Loci and maximum size of thrust Earthquakes and the mechanics of the shallow region of subduction zones. Tectonics 7 : 833-857.

Chaumillon, E.; Mascle, J. 1997. From foreland to forearc domains: new multichannel seismic reflection survey of the Mediterranean Ridge accretionary complex (Eastern Mediterranean). Marine Geology 138: 237-259.

Cobbold, P.R.; Jackson, M.P.A. 1992. Gum rosin (colophony): a suitable material for thermo mechanical modelling of the lithosphere. Tectonophysics 210: 255-271.

Coutand, I.; Cobbold, P.R.; De Urreiztieta, M.; Gautier, P.; Chauvin, A.; Gapais, D.; Rossello, E.A.; LópezGamundí, O. 2001. Style and history of Andean deformation, Puna plateau, northwestern Argentina. Tectonics 20: 210-234. 
Coward, M.P.; Gillcrist, R.; Trudgill, B. 1991. Extensional structures and their tectonic inversion in the Western Alps. In The Geometry of Normal Faults (Roberts, A.M.; Yielding, G.; Freeman, B.; editores). Geological Society, Special Publication 56: 93-113. London.

Dahlen, F.A. 1990. Critical taper model of fold-and-thrust belts and accretionary wedges. Annual Review of Earth and Planetary Sciences 18: 55-99.

Davis, D.; Suppe, J.; Dahlen, F.A. 1983. Mechanics of fold-and-thrust belts and accretionary wedges. Journal of Geophysical Research 88 (B2): 1153-1172.

Davy, P.; Cobbold, P.R. 1988. Indentation tectonics in nature and experiment 1. Experiments scaled for gravity. Bulletin of the Geological Institutions of the University of Uppsala 14: 129-141.

Davy, P.; Cobbold, P.R. 1991. Experiments on shortening of a 4-layer model of the continental lithosphere. Tectonophysics 188: 1-25.

De Urreiztieta, M.; Gapais, D.; Le Corre, C.; Cobbold, P.R.; Rossello, E.A. 1996. Cenozoic dextral transpression and basin development at the southern edge of the Puna plateau, NW Argentina. Tectonophysics 254: 17-39.

Ellis, P.G.; McClay, K.R. 1988. Listric extensional fault systems- results of analogue model experiments. Basin Research 1 (1): 55-70.

Galland, O.; Cobbold, P.R.; De Bremond d'Ars, J.; Hallot, E. 2003. Physical models of magmatic intrusion during thrusting. Terra Nova 15: 405-409.

Galland, O.; Cobbold, P.R.; Hallot, E.; De Bremond d'Ars, J.; Delavaud, G. 2006. Use of vegetable oil and silica powder for scale modelling of magmatic intrusion in a deforming brittle crust. Earth and Planetary Science Letters 243 (3-4): 786-804.

Gartrell, A.P. 1997. Evolution of rift basins and low-angle detachments in multilayer analog models. Geology 25: 615-618.

Giambiagi, L.B.; Ramos, V.A.; Godoy, E.; Álvarez, P.P.; Orts, S. 2003. Cenozoic deformation and tectonic style of the Andes, between 33 and 34 south latitude. Tectonics 22 (4): 1041-1059. doi: 10.1029/2001TC001354.

Gomes, C.J.S. 2013. Investigating new materials in the context of analog physical models. Journal of Structural Geology 46: 158-166.

Graveleau, F.; Malavieille, J.; Domínguez, S. 2012. Experimental modelling of orogenic wedges: a review. Tectonophysics 538-540: 1-66. doi: 10.1016/j. tecto.2012.01.027.

Horsfield, W. 1977. An experimental approach to basementcontrolled faulting. Geologie en Mijnbouw 56: 363-370.
Hubbert, M.K. 1937. Theory of scale models as applied to the study of geologic structures. Geological Society of America Bulletin 48 (10): 1459-1520.

Huiqi, L.; McClay, K.R.; Powell, D. 1992. Physical models of thrust wedges. In Thrust Tectonics (McClay, K.R.; editor). Chapman and Hall: 71-81. London.

Isacks, B.L. 1988. Uplift of the Central Andean Plateau and bending of the Bolivian Orocline. Journal of Geophysical Research 93: 3211-3231.

Jara, P.; Likerman, J.; Winocur, D.; Ghiglione, M.C.; Cristallini, E.O.; Pinto, L.; Charrier, R. 2015. Role of basin width variation tectonic inversion: insight from analogue modelling and implications for the tectonic inversion of the Abanico Basin, $32-34^{\circ} \mathrm{S}$, Central Andes. In Geodynamic Processes in the Andes of Central Chile and Argentina (Sepúlveda, S.A.; Giambiagi, L.B.; Moreiras, S.M.; Pinto, L.; Tunik, M.; Hoke, G.D.; Farías, M.; editores). Geological Society of London, Special Publications 399: 83-107. doi: 10.1144/SP399.7.

Jara, P.; Likerman, J.; Charrier, R.; Herrera, S.; Pinto, L.; Villarroel, M.; Winocur, D. 2018. Closure type effects on the structural pattern of an inverted extensional basin of variable width: Results from analogue models. Journal of South American Earth Sciences 87: 157-173.

Karig, D.E. 1974. Evolution of arc systems in the Western Pacific. Annual Review of Earth and Planetary Sciences 2: $51-75$.

Konstantinovskaia, E.; Malavieille, J. 2005. Erosion and exhumation in accretionary orogens: Experimental and geological approaches. Geochemistry, Geophysics, Geosystems 6: 1-25. Q02006. doi: 10.1029/2004GC000794.

Kozlowski, E.; Cruz, C.; Sylwan, C. 1997. Modelo exploratorio en la faja corrida de la cuenca neuquina, Argentina. In Simposio Bolivariano, No. 6 "Exploración Petrolera en las Cuencas Subandinas", Memorias I: 15-31. Cartagena de Indias.

Krantz, R.W.1991. Measurements of friction coefficients and cohesion for faulting and fault reactivation in laboratory models using sand and sand mixtures. Tectonophysics 188: 203-207.

Lama, R.D.; Vutukuri, V.S. 1978. Handbook on Mechanical Properties of Rocks 3 (2). Trans Tech Publications: 406 p. Clausthal, Germany.

Lamb, S.; Hoke, L. 1997. Origin of the high plateau in the Central Andes, Bolivia, South America. Tectonics 16: 623-649.

Lohrmann, J.; Kukowski, N.; Adam, J.; Oncken, O. 2003. The impact of analogue material properties on the geometry, kinematics, and dynamics of convergent sand wedges. Journal of Structural Geology 25: 1691-1711. 
Lourenco, L.M. 1991. Particle image velocimetry: photographic and video techniques. VKI Laser Velocimetry 2: $44 \mathrm{p}$.

Marques, F.O.; Cobbold, P.R. 2002. Topography as a major factor in the development of arcuate thrust belts: insights from sandbox experiments. Tectonophysics 348 (4): 247-268.

Martínez, F.; Cristallini, E. 2017. The doubly vergent inverted structures of the Mesozoic basins of northern Chile $\left(28^{\circ} \mathrm{S}\right)$ : a comparative analysis from field data and analogue modeling. Journal of South American Earth Sciences 77: 327-340. doi: 10.1016/j.jsames.2017.02.002.

Martínez, F.; Bonini, M.; Montanari, D.; Corti, G. 2016. Tectonic inversion and magmatism in the Lautaro Basin, northern Chile, Central Andes: A comparative approach from field data and analog models. Journal of Geodynamics 94-95: 68-83.

McClay, K.R. 1990. Extensional fault systems in sedimentary basins: a review of analogue model studies. Marine and Petroleum Geology 7: 206-233.

McClay, K.R. 1995. The geometries and kinematics of inverted fault systems: a review of analogue model studies. Geological Society of London, Special Publications 88 (1): 97-118.

McClay, K.R.; Buchanan, P.G. 1992. Thrust faults in inverted extensional basins. In Thrust tectonics (McClay, K.R.; editor). Chapman and Hall: 93-114. Londres.

McClay, K.R.; Whitehouse, P.S. 2004. Analog modeling of doubly vergent thrust wedges. In Thrust tectonics and hydrocarbon systems (McClay, K.R.; editor). Association of Petroleum Geologists, Memoir 82: 184-206.

Mitra, S. 1993. Geometry and kinematic evolution of inversion structures. American Association of Petroleum Geologists, Bulletin 77: 1159-1191.

Moore, J.C.; Karig, D.E. 1976. Sedimentology, structural geology, and tectonics of the Shikokou subduction zone, SW Japan. Geological Society of America Bulletin 87: 1259-1268.

Morgan, J.K. 2015. Effects of cohesion on the structural and mechanical evolution of fold and thrust belts and contractional wedges: Discrete element simulations. Journal of Geophysical Research: Solid Earth 120 (5): 3870-3896. doi: 10.1002/2014JB011455.

Mulugeta, G.; Koyi, H. 1987. Three-dimensional geometry and kinematics of experimental piggyback thrusting. Geology 15: 1052-1056.

Mulugeta, G. 1988. Modelling the geometry of Coulomb thrust wedges. Journal of Structural Geology 10: 847-859.
Mulugeta, G.; Koyi, H. 1992. Episodic accretion and partitioning in a model sand wedge. Tectonophysics 202: 319-333.

Muñoz, J.A. 1992. Evolution of a continental collision belt: ECORS-Pyrenees crustal balanced cross-section. In Thrust Tectonics (McClay, K.R.; editor). Chapman and Hall: 235-246.

Panien, M.; Schreurs, G.; Pfiffner, A.O. 2006. Mechanical behaviour of granular materials, used in analogue modelling: insights from grain characterisation, ring-shear tests and analogue experiments. Journal of Structural Geology 9: 1710-1724.

Payrola, P.A. 2012. Andean oblique folds in the Cordillera Oriental-Northwestern Argentina: Insights from analogue models. Journal of Structural Geology 42: 194-211.

Pérez, F. 2019. Captura y procesamiento de datos analógicos mediante PIV. Memoria de Título (Inédito), Universidad de Santiago de Chile, Departamento de Matemática y Ciencia de la Computación: 83 p.

Perkins, J.P.; Ward, K.M.; De Silva, S.; Zandt; G., Beck, S.; Finnegan, N.J. 2016. Surface uplift in the Central Andes driven by growth of the Altiplano Puna Magma Body. Nature Communications 7: 13185. doi: 10.1038/ ncomms 13185.

Pinto, L.; Muñoz, C.; Nalpas, T.; Charrier, R. 2010. Role of sedimentation during basin inversion in analogue modeling. Journal of Structural Geology 32: 554-565.

Pollard, D.; Fletcher, R.C. 2005. Fundamentals of Structural Geology. Cambridge University Press: 500 p.

Ramberg, H. 1981. Gravity, Deformation and the Earth's Crust. In Theory, Experiments and Geological Application. Academic Press: 452 p. London.

Ramos, V.A. 1985. El Mesozoico de la Alta Cordillera de Mendoza: Reconstrucción tectónica de sus facies. In Congreso Geológico Chileno, No. 4, Actas 1: 104117. Antofagasta.

Ramos, V.A. 1999. Rasgos estructurales del territorio argentino. Geología Argentina (Caminos, R.; editor). Instituto de Geología y Recursos Minerales, Anales 29 (24): 715-784.

Ramos, V.A.; Aguirre-Urreta, M.B.; Álvarez, P.; Cegarra, M.; Cristallini, E.; Kay, S.M.; Lo Forte, G.; Pereyra, F.; Pérez, J. 1996. Geología de la región del Aconcagua, provincias de San Juan y Mendoza. Subsecretaría de Minería de la Nación, Dirección Nacional del Servicio Geológico, Anales 24 (14): 387-422. Buenos Aires.

Roeder, D.; Chamberlin, R.L. 1995. Structural geology of sub-Andean fold-and-thrust belt I northwestern Bolivia. In Petroleum basins of South America (Tankard, A.J.; Suárez Soruco, R.; Welsink, H.J.; editores). American 
Association of Petroleum Geologists, Memoir 62: 459-479.

Roperch, P.; Fornari, M.; Hérail, G.; Parraguez, G.V. 2000. Tectonic rotations within the Bolivian Altiplano: implications for the geodynamic evolution of the central Andes during the late Tertiary. Journal of Geophysical Research 105: 795-820.

Schellart, W.P. 2000. Shear test results for cohesion and friction coefficients for different granular materials: scaling implications for their usage in analogue modelling. Tectonophysics 324: 1-16.

Schellart, W.P.; Strak, V. 2016. A review of analogue modelling of geodynamic processes: Approaches, scaling, materials and quantification, with an application to subduction experiments. Journal of Geodynamics 100: 7-32.

Silver, E.A.; Ellis, M.J.; Breen, N.E.; Shipley, T.H. 1985. Comments on the growth of accretionary wedges. Geology 13: 6-9.

Thielicke, W.; Stamhuis, E.J. 2014. PIVlab-towards user-friendly, affordable and accurate digital particle image velocimetry in MATLAB. Journal of
Open Research Software 2 (1): e30. doi: 10.5334/ jors.bl .

Torrini, R.; Speed, R.C. 1989. Tectonic wedging in the forearc basin-accretionary prism transition, Lesser Antilles forearc. Journal of Geophysical Research 94: 10549-10584.

Turienzo, M. 2010. Structural style of the Malargüe foldand-thrust belt at the Diamante River area (34 $30^{\circ}$ $34^{\circ} 50^{\prime}$ 'S) and its linkage with the Cordillera Frontal, Andes of central Argentina. Journal of South American Earth Sciences 29: 537-556.

Twiss, R.J.; Moores, E.M. 2007. Structural Geology. Freeman and Co.: 736 p. New York.

Yamada, Y.; McClay, K.R. 2003. Application of geometric models to inverted listric fault systems in sandbox experiments. 1: 2D hanging wall deformation and section restoration. Journal of Structural Geology 25: 1551-1560.

Yamada, Y.; McClay, K.R. 2004. 3-D Analog modeling of inversion thrust structures. In Thrust Tectonics and Hydrocarbon Systems (McClay, K.R.; editor). American Association of Petroleum Geologists, Memoir 82: 276-301. 